\title{
Chapter 2 \\ Formal Semantic-Discursive and Pragmatic Assessments of Temporal Reference
}

\subsection{The Formal Semantic-Discursive Account}

Temporal cohesive ties-whether taken individually or as components contributing to the meaning of verbal tenses-has received extensive attention from scholars working in formal-semantic and pragmatic approaches to discourse. Various studies have aimed to explain and model the role of Tense, Aspect and Aktionsart in constructing the structure and the meaning of a discourse, either by focusing on the semantic meaning and making use of semantic rules, such as Bennet and Partee (1978), Dowty (1972), Kamp (1979), Kamp and Reyle (1993), Lascarides and Asher (1993), or by focusing on the contextually determined meaning of these semantically underdetermined categories in order to build the speaker's intended meaning, such as Grice (1967, 1975, 1989), Sperber and Wilson (1986), Levinson (2000), Moeschler et al. (1998) and de Saussure (2003). This chapter assesses these approaches to time and to temporal information at the discursive level, and highlights the relevance-theoretic approach to verbal tenses. Based on these accounts, a series of hypotheses regarding the nature of the meaning of Tense, Aspect and Aktionsart and their roles at the discursive levels are formulated and tested in annotation experiments (Chap. 4). These experiments provide new evidence that partially validate and partially challenge the theoretical accounts discussed in the present chapter.

In Sect. 1.2.1, I noted that Tense was treated as a logical operator in Prior's tense logic. The semantic interpretation of the operators PRES, PAST and FUT was further developed by Bennett and Partee (1978) in a non-compositional semantic model. Their system is non-compositional in that it provides different semantic interpretations rules for verbal tenses in English, such as the Present Perfect, the Past Perfect, the Present Perfect Progressive, and so on. As for the aspectual operators PERFective and PROGgressive, they were analysed by Dowty (1972) in a compositional semantic model. Bennett and Partee's (1978) theory has the basic 
assumptions that expressions and sentences must be judged in terms of their truthvalue, and that temporal operators have scope over the whole sentence. Their treatment recalls Reichenbach's system (1947) of temporal coordinates and temporal relations. Their model makes use of the following elements (adapted from Binnick 1991, 253):

$T$, which is the set of all instants of time $t$;

Temporal ordering relations (earlier $<$, later $>$ and identical $=$ ) so that two members of $\mathrm{T}, t_{1}$ and $t_{2}$ can be $t_{1}<t_{2}$ or $t_{1}>t_{2}$ or $t_{1}=t_{2}$.

$I$, which is an interval of $T$ (a subset with no gaps) that can be bounded (i.e. has an initial and a final boundary) or open-ended (signalled by the symbol $\infty$ ); an interval with only one member $t$ is called a moment of time. Let $I$ be an interval between points $t_{1}$ and $t_{2}$, which are its first and the last moments. Let $I^{\prime}$ be a member of [T]. I is a proper subinterval of $I^{\prime} \quad$ iff $\mathrm{I} \in[\mathrm{T}]$ and $I \subset I^{\prime} \quad$ (that is, $\mathrm{I} \subseteq I^{\prime}$ and $I \neq I^{\prime}$ ). When an interval I wholly precedes an interval $I^{\prime} \quad$ (that is, the final point $t$ of $I$ and the initial point $t^{\prime}$ of $I^{\prime}$ are such that $\mathrm{t}<t^{\prime}$ ), we write $I[<] I^{\prime}$.

For Bennett and Partee, the evaluation in terms of truth conditions of a sentence, with respect to the temporal localization of eventualities in time, is relative not to a point or a moment $t$ but to an interval $I$. For example, the sentence John is reading is true at noon, but the sentence John is building his dream house cannot be true at noon, and is instead true relative to an interval of time. With this proposal, Bennett and Partee point to the interaction between Tense and Aspect on the one hand (treated as temporal operators in their model) and Aktionsart on the other hand, which requires an extended period of time for states, activities and accomplishments. For example, for Bennett and Partee, the truth conditions of the simple past are as follows:

John eat fish $\alpha$ is true at interval of time I if and only of I is a moment of time. $\alpha$ refers to an interval of time $I^{\prime}$ and there exists a subinterval of $I^{\prime}, I^{\prime \prime}$, such that $I^{\prime \prime} \quad[<] I$ and John eats the fish is true of $I^{\prime \prime}$. (Bennett and Partee 1978,13)

If $\alpha$ is yesterday, the interval $I^{\prime}$ is the time frame corresponding to yesterday, during which the event occurred, and $I$ is the interval corresponding to today. The subinterval $I^{\prime \prime}$ is the event time, and is included in $I^{\prime}$. Binnick $(1991,256)$ argues that the condition for $I^{\prime \prime}$ to be a proper subinterval of $I^{\prime}$ does not seem to be obligatory, as in example (319), where the frame time at the precise moment when John opened the door, Sue was kissing Igor is a moment which follows from the meaning of the adverbial when.

\section{When John opened the door, Sue was kissing Igor.}

Also building on Reichenbach's model for verbal tenses, McCawley (1971), Partee (1973, 1984), Hinrichs (1986), Nerbonne (1986) and Webber (1988), among others, accounted for verbal tenses and their discursive function as temporal anaphors. In these formal semantic theories, temporal information is not a sentence specific feature, but a relational feature applying beyond sentence boundaries. Partee $(1973,244-247)$ justifies the notion of temporal anaphora by pointing to a series of common features between temporal and pronominal anaphora, such as no 
necessity for a linguistic antecedent (as in the pair of examples in (320) and (321), where the former is the temporal anaphor and the latter the pronominal anaphor), the existence of a definite antecedent for a definite anaphor (which is the same time in the case of temporal anaphor, as in (322), and the same referent in the case of pronominal anaphor, as in (323)), the possibility to have an indefinite antecedent (both for temporal anaphor, as in (324), and for pronominal anaphor, as in (325)), and the fact that both pronouns and temporal anaphors can act as bound variables (that is, bounded by a quantifier, as in (326) and (327) respectively).

I didn't turn on the oven.

(322) Sheila had a party last Friday and Sam got drunk.

(323) Sam is married. He has three children.

(324) Mary woke up some time during the night. She turned on the light.

(325) Pedro owns a donkey. He beats it.

Whenever Mary telephoned, Sam was asleep.

Every woman believes that she is happy.

In these accounts, Reichenbach's reference time and Kamp's (1979) system of discourse representation structures are centred on the treatment of temporal anaphora. Kamp's theory, the Discourse Representation Theory, or DRT for short, is a formal semantic theory that considers the articulation between the truth conditions of sentences (which, according to model-theoretic semantics based on Montague Grammar, depends on the connection between the meaning of the expression uttered on the one hand, and on its factuality on the other) and the phenomenon of language interpretation (Kamp 1979, 1981, Kamp and Reyle 1993). ${ }^{1}$ In DRT, Kamp and Reyle assume that the interpretation of sentences and texts is constructed in the form of abstract structures that they call discourse representation structures, or DRSs. DRSs are logically related and built by applying certain rules, called DRS Construction Rules. A DRS consists of discourse referents (entities that a piece of

\footnotetext{
${ }^{1} \mathrm{~A}$ more recent proposal in this vein is made by Bittner (2014), who speaks about a universal semantic representation language that she applies to four typologically different languages: English (Tense-based), Polish (Tense-Aspect-based), Mandarin (Aspect-based) and Kalaallisut (Mood-based, Eskimo-Aleut family). Her model of universal typed logic allows a direct typedriven composition using syntactic and semantic rules, which operate in tandem and can thus inform and constrain each other (Bittner 2014, 8). The model, called Categorial Grammar Update with centering, makes use of complex universal algebra and sub-algebra (following Bach 1986; Kamp 1979; Moens and Steedman 1988) of discourse referents (drefs) for individuals, times, eventualities, sets, and worlds. According to her model, in tensed languages as English and Polish, temporal anaphora (to times and sets of times) is parallel to nominal anaphora (to individuals and sets of individuals) and modal (to worlds and sets of worlds). Tenseless languages, like Mandarin and Kalaallisut, refer directly to eventualities, and temporal relations are inseparable from other types of relations between eventualities - mereological, spatial, causal, modal, individual-related, etc. Hence, Bittner suggests that grammatical categories and lexical meanings are language specific (parochial categories in her terms), whereas the syntactic and semantic primitives that all languages use to build their parochial categories and parochial lexical meanings are universal.
} 
discourse is about, functioning as variables) and conditions that apply to these referents.

The main idea of this theory regarding the semantics of coherent multi-sentence discourse and text uttered by the same speaker is that each new sentence of a discourse is interpreted in the context provided by the sentences preceding it-that is, a representation structure (van Eijck and Kamp 1997). DRSs are linguistic units larger than single sentences, but their representation is made sentence by sentence while maintaining the semantic cohesiveness of the discourse or text (Kamp and Reyle 1993). Semantic cohesiveness is provided by various kinds of cross-reference that connect coherent pieces of discourse (Kamp and Reyle 1993, 59). The processing of a piece of discourse is incremental; in the process of comprehension, the interpreter must relate or connect the new sentence to the information structure he has already obtained from the preceding ones. The "old" information structure will be "updated" in the light of the interpretation process, and the updated information structure becomes the new context for the processing of a following sentence, until the entire discourse has been interpreted. This representational and dynamic approach of meaning at the discursive level recalls the psycholinguistic procedural approaches to the meaning of linguistic expressions (Bras 2008 citing Sanford and Garrod 1981, Fodor 1983). Meaning is seen as instructions for incrementally building mental representations of discourse. The procedural nature of the meaning of some linguistic expressions, as well as their role in discourse interpretation was also a topic of debate in Relevance Theory, and among its followers. I will consider in more detail the procedural/conceptual distinction applied to verbal tenses, as well as its integration into the model proposed in this research.

Constructing a DRS for one sentence basically consists of introducing a new discourse referent for the described eventuality, setting the temporal relation between this discourse referent and the time of utterance, introducing a discourse referent $t$ for the time denoted by the adverb (if the sentence contains a temporal adverb), and finally, setting the temporal relation between this discourse referent (constraining information) and the described eventuality (Kamp and Reyle 1993, 514). An additional step specifies the type of the described eventuality (state or event). For example, in example (328), the arrival occurs at some indefinite time on a specific day in the past. Mary's entering the house is linked to the time of the arrival. The interpretation of (328) involves establishing an event discourse referent for the arrival event, and linking it to a reference time discourse referent that points to an interval just after the time of arrival. The processing of the second sentence introduces an event that then must be included in the reference time interval, whose property is to shift the reference time discourse referent from just after the time of arrival to just after the time of the entering of the house.

Mary arrived during the day. She let herself into the house.

Regarding the construction of DRSs for sequences of sentences, and thus temporal ordering such as in (329), Kamp and Reyle $(1993,521)$ argue that 'the eventuality described by a non-initial sentence is interpreted as standing in some specific 
relationship to some other event introduced by an earlier sentence or to some earlier introduced time $t$.' They make use of Reichenbach's temporal coordinates-more specifically, of the reference point $\mathrm{R}$ in the form of a new condition $\alpha$ that represents a time or an event that is already present in the DRS. Following this idea, interpreting the second sentence (with a progressive verb form, and describing a state) involves establishing that the $\alpha$ from the first sentence is included in the reference point of the second one, hence leaving $\mathrm{R}$ unchanged. For the processing of the third sentence (with a simple past tense, and describing an event), the relation is not that of inclusion but that of succession: the reference point of the current interpreted sentence temporally succeeds the reference point of the preceding ones.

(329) A man entered the White Hart. He was wearing a black jacket.

Bill served him a beer.

For Kamp and Rohrer, verbal tenses encode information about how to establish the temporal reference of an eventuality, related to a reference point and to other eventualities in a discourse. In a text containing a succession of sentences whose main verb is in the Passé Simple or Passé Composé, the order of the sentences corresponds to the order of the events. The same principle can be applied when interpreting a succession of events in a complex sentence. The Passé Simple and the Imparfait thus encode interpretation rules: a Passé Simple introduces a new event representation with a reference point that succeeds the reference point of the previous sentence, whereas an Imparfait introduces a new state representation, which covers a period that includes the reference point of the event introduced previously by a Passé Simple or a Passé Composé. The Passé Simple encodes a forward temporal inference, the plus-que-parfait encodes a backward inference, and the Imparfait encodes an inclusive temporal inference. Unfortunately, this idea has numerous counterexamples discussed by Kamp and Rohrer (1983, 260) themselves, as in (330), as well as by Moeschler (2000a, 2000b), de Saussure (1997, 2000a, b) and Tahara (2000) for the Passé Simple, and de Saussure and Sthioul $(1999,2005)$ for the Imparfait, among others.

(330) Bianca chanta et Pierre l'accompagna au piano.

'Bianca sang and Peter accompanied her on the piano.'

Kamp and Rohrer therefore propose a predictive model for interpreting the Passé Simple (time moves forward) and Imparfait (time stagnates), and they put forward some of the exceptions to the rules, explained in terms of the complexity of temporal indexicality and the role of temporal adverbs in building DRs, as well as the notions of temporal and personal perspectives on eventualities. Within DRT, only sentential syntax and the compositional semantics of the DRSs affect the interpretation of temporal anaphora. Lascarides and Asher (1993) emphasize that, in DRT, forward movement of time is encoded in the logical form of the clauses through the forward movement of their reference times, while statives do not encode this information. One of the limits of DRT is the fact that the semantic rules provided are too 
specific, and limit the extent to which the model they suggest can cover the empirical data (Kamp and Rohrer 1983). Lascarides and Asher (1993) propose counterexamples to the DRT analysis such as 'Max fell. John pushed him.', where the temporal order of events mismatches their textual order, and thus rules for constructing the logical form yield a DRS with wrong truth conditions.

These limits have been considered by the Segmented Discourse Representation Theory, or SDRT for short, which was developed to elaborate on DRT in the beginning of the 1990s (Lascarides and Asher 1993; Asher and Lascarides 2003) and proposes a certain number of refinements to solve various problems, among them the problems mentioned by Kamp and Rohrer (1983). SDRT, offering a formal account of the hypothesis that discourse has a hierarchical structure upon which interpretation depends, was well received, and soon accepted as the most elaborated semantic alternative to pragmatic models of temporal interpretation at the discursive level. SDRT addresses temporal relations among discourse segments (sentences in SDRT and mental representations in DRT) according to the context (consisting of cotext and world knowledge in SDRT, compared to only cotext in DRT).

Despite the strengths of this theory, such as a complete system of rules that can produce each of the proposed discourse relations, the awareness of and the modelization of the fact that the human mind must make a decision between two possible interpretations by cancelling the default interpretation and favouring the most specific one (de Saussure 2003), SDRT is a coherence-driven theory (Kehler 1994, 2004). Precisely, it posits that temporal relations are resolved "purely as a byproduct of reasoning about coherence relations holding between utterances", hence "treating simple and complex tenses as anaphoric is unnecessary" as pointed out by Kehler $(1994,1)$. Further limits relate to a lack of correspondence between the model and real linguistic situations, as well as to its lack of cognitive likelihood (de Saussure 2003). Firstly, the logical rules can have an extreme degree of specificity that renders the model very complex and even ambiguous, and for this reason, they should be replaced by general pragmatic principles which are activated contextually, and based on the addressee's world knowledge. A second issue is that of the default narration relation. For example, for the narration relation to take place, a minimal set of conditions is required, such as a conceptual relation and the occurrence of verb tenses that provide instructions for the progress of time in that specific context. Hence, discourse relations seem to be the consequence of - rather than the reason for-temporal interpretation, as argued by Moeschler (1998a). Another proposal is made by de Saussure (2003), using a procedural pragmatic framework which postulates that verbal tenses encode instructions on how to interpret discourses temporally (cf. Sect. 2.3.3.)

Other scholars (Jespersen 1924; Dry 1981, 1983; Dowty 1986; ter Meulen 1997; C. Smith 2003) have focused on the role of the aspectual classes of the verb phrase in determining the temporal relations between sentences in discourse. Dowty (1986) builds his model on narrative texts, and argues (p. 37) that there is temporal progression with accomplishments and achievements, as in (331) and (332), and a lack of temporal progression with activities and states, as in (333) and (334). 
(331) John entered the president's office. The president walked over to him.

(332) John entered the president's office. The president woke up.

(333) John entered the president's office. The president sat behind a huge desk.

(334) John entered the president's office. The clock on the wall ticked loudly.

In his words,

If a sentence in a narrative contains an accomplishment or achievement predicate but no definite time adverb, that sentence is understood to describe an event occurring later than the time of the previous sentence's event (...narrative time "moves forward" in the second sentence)...If on the other hand the second sentence of the sequence has a stative or an activity predicate, the state or process it describes is most usually understood to overlap with that of the previous sentence: narrative time does not "move" in the second sentence. (Dowty 1986, 37)

Dowty gave an initial exception to this rule: that of the progressive. Specifically, when a progressive form is used, the sequence is interpreted as lacking temporal advancement, no matter what the aspectual class of the verb phrase is, such as an activity, as in (335) and (336).

(335) John entered the president's office. The president was looking out the window.

(336) John entered the president's office. The president was writing a letter.

Another exception is that of certain lexical stative verbs (e.g. stand, sit, realize) which are ambiguous between a stative and an inceptive interpretation. With the inceptive interpretation, they behave like achievement verb phrases, and determine the temporal progression in discourse, as in (337). Other stative verbs can receive an inceptive interpretation with adverbials such as suddenly or in a moment, leading to temporal progression, as in (338).

(337) John entered the president's office. The president realized why he had come.

(338) John sat in his chair going over the day's perplexing events again in his mind. Suddenly, he was asleep.

Dowty proposed that temporal information in discourse depends on sentence semantics (which includes determining aspectual classes) and pragmatic principles. He claimed that the temporal relationships between sentences of a discourse are determined by three factors:

- Semantic analysis of aspectual classes using the interval semantics model (Taylor 1977, Dowty 1979). The main idea of the model is that recursive semantic clauses are to be stated in terms of the notions of truth of a sentence with respect to an interval of time. The truth of a sentence with respect to a given interval I is independent of the truth of that same sentence with respect to either subintervals of I, or moments within I or superintervals of I. 
- The Temporal Discourse Interpretation Principle (TDIP)

- Gricean conversational implicatures and the "common sense" principle

Dowty $(1979,1986)$ argued that it is the aspectual class of the whole sentence (rather than any of its constituents) that is relevant to the temporal effect on discourse interpretation. Dowty's idea is that the aspectual class of a phrase or a sentence is determined in a mechanical and completely explicit way by the lexical aspectual class of its main verb, noun phrases, adverbials, tenses and other constituents, by way of compositional semantic rules. The sentence in (339) is an example of the computation of the aspectual class of the sentence: walk is an activity; walk to the station is an accomplishment; and the whole sentence is stative because of its progressive form.

John was walking to the station.

Based on this observation, Dowty proposed the TDIP for temporally interpreting successive sentences in a discourse. The TDIP postulates that the reference time ${ }^{2} R$ of a sentence in a sequence of sentences is to be interpreted as consistent with the definite time adverbials occurring in the sentence (if there are any), and otherwise with a time immediately preceding the reference time of the previous sentence. Dowty points out that the time distance between the $\mathrm{R}$ points of the two sentences is determined by pragmatic principles, such as the hearer's understanding of the nature of the events related, the overall degree of detail in which events are being described, and common knowledge about the usual temporal relations among events.

According to the interval semantics model, when a sentence with an accomplishment or achievement interpretation is true at an interval I, it is false at all subintervals, and at all superintervals of I (by entailment). For sentences with an accomplishment or achievement reading, TDIP thus predicts that the sequence of sentences must be interpreted as non-overlapping intervals. Consequently, there is temporal progression.

The case of states and activities is different in this respect. Again, according to the interval semantics model, when a sentence with a stative/activity interpretation is true at an interval I, it is true at all subintervals of I. The model makes no prediction for the superintervals of I, thus allowing for sentences with a stative interpretation to be true at all superintervals of I, as in (340).

(340) John was asleep from $1 \mathrm{pm}$ to $2 \mathrm{pm}$; in fact, he fell asleep at noon and did not wake up until $3 \mathrm{pm}$.

For sentences with a stative/activity reading, TDIP thus predicts that the sequence of sentences must be interpreted as overlapping intervals. Consequently, there is no

\footnotetext{
${ }^{2}$ For Dowty (1982), reference time $\mathrm{R}$ and speech time $\mathrm{S}$ are contextual parameters of the utterance.
} 
temporal progression, as in (341). The situation is different in (342), where the causal relation between the first and the second sentences cancels the overlapping interpretation of the look out the window activity.

(341) John entered the president's office. The clock ticked loudly.

(342) John asked were the children were. Mary looked anxiously out the window.

Their coats lay on the lawn, but they were not in sight. (Dry 1983)

As far as the interpretation of sequences of sentences containing the progressive or expressing iterative or habitual aspect, Dowty (as well as Dry 1983) assumes that they behave as stative sentences. The TDIP predicts no temporal progression, as in (343) and (344).

(343) John entered the president's office. The president was writing a letter.

(344) John entered the president's office. They played football together on Sundays.

Kozlowska (1998a, 1998b) and Moeschler (1998b) gave arguments against Dowty's hypothesis that aspectual classes determine the temporal structure of a discourse. Sentences (333) and (334) have a temporal progression interpretation if the verbal tense is changed, as shown in the French examples in (344) and (345), where a Passé Simple form is used corresponding to the inceptive reading of to sit and to tick (Kozlowska 1998a, 117). Dowty himself points out that the effect of the aspectual class of temporal interpretation can be cancelled by an inceptive reading, introduced for example by an adverbial such as suddenly, as already shown in (338).

(345) Jean entra dans le bureau du président. Le président s'assit derrière un énorme bureau.

'John entered the president's office. The president sat behind a huge desk.'

(346) Jean entra dans le bureau du président. L'horloge murale marcha bruyamment.

'John entered the president's office. The clock ticked loudly.'

There are some cases where the temporal interpretation predicted by the TDIP does not apply, such as cases where the second sentence in a discourse describes the same situation but in a more detailed manner, as in (347), cases where a simultaneous interpretation is inferred from the context, as in (348), cases where the second sentence describes subevents of the situation expressed in the first sentence, as in (349), and cases where a progressive expresses the speaker's subjective viewpoint, as in (350).

(347) John knelt at the edge of the stream and washed his face and hands.

He washed slowly, feeling the welcome sensation of the icy water on his parched skin. (Dowty, 1986, 58 citing Dry 1983) 
(348) At the signal, every one went to work at once. Mary searched the room for any of the items of the list that might be there. John went next door to do the same in Bill's apartment. (Dowty 1986, 58)

(349) Pedro dined at Madame Gilbert's. First there was an hors d'oeuvre. Then the fish. After that the butler brought a glazed chicken. The repast ended with a flaming desert. (Dowty 1986, 58 citing Kamp)

(350) In the darkness, John felt his way up the stairway of the dilapidated old house. Halfway, there was a loud cracking noise under his feet, and suddenly he was falling through space. (Dowty 1986, 55)

Dowty points out that the TDIP may be considered to describe the 'default' cases of discourse interpretation, and is applicable when the discourse does not provide other sources of temporal information which have priority, such as time adverbials, entailments and implicatures regarding the ordering of events.

Smith $(2007,2008)$ suggested an aspectual model of discourse interpretation for tenseless and mixed-temporal languages. She proposed a model for Mandarin Chinese developed according to the DRT framework (Kamp and Reyle 1993). She includes syntactic, semantic and pragmatic components, and also makes use of contextual information. The syntactic component is the functional ASP-P node of the syntactic structure. The two semantic components are Aspect (perfective, imperfective and neutral viewpoints) and Aktionsart (realized by the verbs and its arguments). The pragmatic component is represented by the default inferences about temporal localization of eventualities.

The viewpoints introduce the reference time $R$, the event moment $\mathrm{E}$ and the relation between the two, as well as boundedness information, which is represented by conditions relating the situation time interval to the entity $\mathrm{E}$ (information specified by the construction rules). Perfective viewpoints introduce a bounded eventuality, imperfective viewpoints introduce an unbounded eventuality, and finally, neutral viewpoints provide information that the situation is only partially visible (i.e. there is no information regarding boundaries). Moreover, lexical aspect conveys boundedness in zero-marked sentences containing a neutral viewpoint: punctual and telic eventualities (i.e. accomplishments and achievements) are bounded, whereas ongoing events (i.e. activities) and states are unbounded.

The third temporal coordinate involved in temporal reference, the moment of speech $\mathrm{S}$, is introduced into the DRS for each clause automatically (Kamp and Reyle 1993). R's relation to $\mathrm{S}$ is established by pragmatic inference. By default, bounded situations are located as precedeing $\mathrm{S}$ (i.e. in the past) and unbounded situations are located as co-occuring with $\mathrm{S}$ (i.e. in the present). These default inferences may be overridden by additional information. The pragmatic principles that underlie Smith's account of temporal reference are the Deictic Principle, the Bounded Event Constraint and the Simplicity Principle of Interpretation.

Ter Meulen's Dynamic Interpretation of Tense and Aspect (1995/1997) is a discourse semantics approach to temporal reference based on the role played by aspectual classes, and used to interpret sentences in a discourse dynamically. Her 
suggestion is that aspectual classes and their aspectual properties determine how the events are temporally related in a discourse, and that this aspectual information 'controls the dynamics of the flow of information about described change encoded in text' $(1997,6)$. She redefines the well-known aspectual classes as holes (i.e. activities such as drive around, pour, damage), filters (i.e. accomplishments such as walk a mile, drive home, land) and plugs (i.e. achievements such as arrive, finish, begin). Similar to the DRT and SDRT frameworks, ter Meulen assumes that sentences are interpreted at the level of the discourse: each sentence is interpreted according to the information provided by the previous ones. For example, if a given sentence is interpreted as describing an event as a hole, then the information expressed in the following sentence is interpreted as being part of that event 'as if information it conveys flows through the hole' (p. 7). When a sentence is interpreted as a filter, then it restricts the information in the following sentence to describe another simultaneous situation. Finally, when a sentence is interpreted as a plug, it blocks any information about a simultaneous situation. Hence, the context must redirect its temporal direction by interpreting the next sentence as describing another later event.

Ter Meulen points out that factors such as Tense, Aspect, noun phrases, prepositional phrases and verbal arguments (as previously discussed by Depraetere 1995a) interact with verbs when it comes to determining their aspectual class, and therefore their function as holes, filters or plugs. Moreover, causal connections or other knowledge of the world can modify and overrule these general semantic principles. Temporal reasoning, a form of logical reasoning, requires that premises supposed to be true trigger conclusions supposed to be true if the argument is valid. The temporal information manipulated in logical reasoning can come from three sources: (i) the descriptive content of the utterance; (ii) aspectual classes; and (iii) perspectival information (i.e. provided by grammatical aspect). In ter Meulen's model, these types of temporal information are modelled as ordered representations of information, obtained according to rules provided by Dynamic Aspect Trees (DATs). Two other important elements in the study of temporal reasoning in ter Meulen's model are temporal adverbials and verbal tenses. For example, events described by simple past tense clauses and interpreted as filters and plugs affect the perspective by shifting the temporal vantage point. In example (351), the third sentence is interpreted as a different event, occurring after the event from the first sentence. In contrast, the event that caused the perfect state in the second sentence must precede both the simple past events from the first and third sentences. From (351), one can legitimately infer (352) (as pointed out by ter Meulen 1997, 15).

(351) The car hit the fence. The driver had been killed. The police arrived.

(352) The driver was killed before his car hit the fence and before the police arrived.

Similarly, Boogaart (1999), investigating the role played by Aspect and Aktionsart in determining the temporal ordering of eventualities in English and Dutch, suggested that Aspect does not determine the temporal interpretation of a discourse, but 
allows both temporal sequencing and temporal simultaneity. In Boogaart's model, there are several factors that influence the temporal interpretation of a discourse containing reference to past time, such as Aktionsart (states vs. events), Aspect (perfective vs. imperfective), discourse type (narrative vs. non-narrative) and pragmatic incompatibility (i.e. an interpretation is pragmatically incompatible with an utterance if it is not supported either by world knowledge, or by the cooperative principle and maxims in the sense of Grice).

\subsection{The Gricean Account}

Grice $(1967,1975,1989)$ challenged the classical view that pragmatics is concerned only with the nonconventional or contextual meaning, such as irony and metaphor. He moved the focus from the conventional vs. nonconventional distinction to the truth-conditional vs. non-truth-conditional distinction. Truth-conditional meaning is expressed by what is said and belongs to the domain of semantics, while nontruth-conditional meaning is expressed by what is implicated (i.e. implicature) and belongs to the pragmatic domain. Grice thus establishes a fixed border between the two domains. One of the consequences of this position is that implicated meanings do not contribute to the truth-conditions of utterances. An initial distinction proposed by Grice is between conventional implicatures and conversational implicatures. Conventional implicatures are triggered by specific expressions. In (353), the speaker implies that his friend and his colleagues will most probably go to prison in the near future. This implicature is triggered by the adverbial yet.

(353) How is your friend doing? Oh quite well, I think; he likes his colleagues, and he hasn't been to prison yet.

Conversational implicatures occur in discourse, and are the result of the application of conversational maxims or the conversation principle. They can either be triggered by specific words (i.e. generalized conversational implicature), as in (354), where the meaning of and is the temporal meaning 'and then', or not (i.e. particularized conversational implicature), as in (365), where B implicates that the A will find petrol at the garage round the corner.

(354) I took out the key and opened the door.

(355) A: I am out of petrol. B: There is a garage round the corner.

Grice $(1975,57-58)$ and Sadock (1978) propose a list of six criteria to test for conversational and conventional implicatures (see Moeschler 2012, 416-417 for a detailed presentation of the six criteria). According to these criteria, conversational implicatures are calculable (originate from a working-out procedure), cancellable, non-detachable, non-conventional, carried out not by what is said but by the speech act, and indeterminate (do not have precise content attached). In contrast, conven- 
tional implicatures are non-calculable, non-cancellable, detachable, conventional, carried out by what is said, and determinate. According to Sadock (1978), and as pointed out by Moeschler, these conditions are neither necessary nor sufficient to test for implicatures, mainly because they are linked to each other.

As shown in (354), temporal (and causal) relations are interpreted as conversational implicatures ${ }^{3}$ (the application of the orderliness maxim). Contrary to what has been suggested by Grice, among others, the temporal and causal relations in sentences (356)-(359) (Wilson and Sperber, 1998; Wilson 2011) are not necessarily triggered by the connective and, since they arise whether it occurs or not in the sentence. $^{4}$

(356) John dropped the glass and it broke.

(357) John dropped the glass. It broke.

(358) Peter left and Mary got angry.

(359) Peter left. Mary got angry.

One of Grice's assumptions was that logical operators such as \& 'and' and their correspondents in natural language (the connective and) are semantically equivalents. A consequence of this assumption is that, if the order of the two conjuncts is reversed, the truth conditions of the utterance do not change. Cohen and Bar-Hillel (1971) pointed out that Grice's treatment of temporal and causal relations as conversational implicatures (thus non-truth-conditional) is inappropriate. The sentence in (360) illustrates that the temporal ordering of the two eventualities is part of the truth-conditions of the utterance, which is what prevents the disjunction in (360) from being redundant.

(360) It's always the same at parties: either I get drunk and no-one will talk to me or no-one will talk to me and I will get drunk.

Following Cohen and Bar-Hillel (1971), Carston (1988) pointed out that what Grice called conversational implicatures were actually truth-conditional (under the scope of logical operators and connectives). Carston convincingly argued that tem-

\footnotetext{
${ }^{3}$ It is worth mentioning the neo-Gricean account of temporal relations, which is similar to the Gricean one, and in particular temporal relations being implicatures triggered by the connective and (Atlas \& Levinson 1981, Levinson 1983, 1987, 1989, 2000; Horn 2004).

${ }^{4}$ Since temporal relations also arise in the absence of the connective and, I have not spoken about it in this research. The reader may refer to Wilson (2011) and Blochowiak (2014a, 2015b) for interesting discussions regarding the puzzles concerning the connective and, defined as five types of problems: sequencing, interval, cause-consequence, unspecified sequence and Horn's problem. Grice's solution for these temporal interpretations triggered by and was the maxim of orderliness. Dowty's solution (1986) was the Temporal Discourse Interpretation Principle. Blochowiak proposes a solution within the relevance theoretic framework by suggesting a finer-grained notion of contextual assumptions (i.e. the Relevance Nomological Model, see Blochowiak 2014b), and by discussing the usages of and with respect to two oppositions: extensionality vs. intensionality; and homogeneity vs. heterogeneity.
} 
poral and causal interpretations are pragmatically determined aspects of what is said, and therefore part of the explicature of the utterance. Advocates of Relevance Theory make the distinction between the explicit meaning of an utterance (i.e. what is said) and the conventional (or "encoded") meaning of the linguistic expressions employed. Wilson and Sperber (1998) assert that temporal and causal 'connotations' in examples (401)-(404) are not encoded in the meaning of the sentences uttered, and follow Carston's idea that they are pragmatically determined aspects of the explicit form of those utterances (i.e. explicatures).

Gibbs and Moise (1997) were the first to conduct an experimental study of ordinary speakers' identification and labelling of what is 'said' vs. what is 'implicated'. In their paper, Gibbs and Moise designed their experiments to determine whether people distinguished what speakers say from what they implicate, and if they viewed what is 'said' as being enriched pragmatically. They used five categories of sentences, ${ }^{5}$ and participants had to choose between a minimal vs. enriched interpretation. Example (361) illustrates the temporal relation type of sentence, as well as the two possible interpretations (minimal or literal meaning, and the pragmatically enriched meaning):

(361) 'The old king died of heart attack and a republic was declared'.

(362) Minimal: order of events unspecified

(363) Enriched: the old king died and then a republic was declared

The experiments were designed to manipulate the type of sentence, the instructions and the context of the targeted sentence. In the first experiment, the instructions consisted in explaining the two types of interpretations of the sentence, and no context was given. In the second experiment, the instructions were more detailed, including information about linguistic theories addressing the distinction between what is 'said' and what is 'implicated'. In the last two experiments regarding temporal relation sentences, linguistic contexts were provided (short stories in order to favour the enriched interpretation (in the third experiment), as in example (364), and the minimal interpretation (in the fourth experiment), as in example (365).

(364) The professor was lecturing on the life of Jose Sebastian.

He was a famous rebel in Spain who fought to overthrow the King.

Many citizens wanted Sebastian to serve as their President.

"Did Jose Sebastian ever became President?" one student asked.

The professor replied, The old king died of a heart attack before and a republic was declared.

(365) Mike liked to take long bike rides each day. He also liked to sing as he rode because he has a terrific voice. Mike's roommate thought this was funny. He said to someone that Mike likes to ride his bike and sing at the top of his lungs.

\footnotetext{
${ }^{5}$ Cardinal (Jane has three children), possession (Robert broke a finger last night), scalar (Everyone went to Paris), time-distance (It will take us some time to get there) and temporal relations.
} 
Gibbs and Moise's four experiments showed that speakers assume that enriched pragmatics plays a significant role in what is said: the enriched interpretation was preferred in the first three experiments, but not in the last one, where the context caused a strong bias in favour of the minimal interpretation. Manipulation of the instructions and training did not have any effect on the participants' judgements.

Three observations can be made concerning the temporal relation type of sentences: (a) temporal sequencing is an inference drawn contextually ${ }^{6}$; (b) it is independent of the specific instructions that speakers received; and (c) it can be blocked in a context providing a bias in favour of the minimal interpretation (that is, the unspecified order). On the basis of their results, Gibbs and Moise argue that there might be two types of pragmatic processes: one that provides an interpretation for what speakers say; and another that provides an interpretation for what speakers implicate. They argue that this position can be explained by the principle of optimal relevance (Sperber and Wilson 1986), although they acknowledge the difficulty of testing it experimentally.

Based on these observations, Relevance Theory (in particular, Carston 1988) proposes that the temporal and causal interpretations of such sentences should be analysed as pragmatically determined aspects of what is said. In other words, there are aspects of what is linguistically encoded that are pragmatically determined. This remark is linked to the proposal in Relevance Theory of the inferential model of communication (consisting of two phases: decoding and inference), and to the conceptual vs. procedural distinction of types of encoded information (Blakemore 1987).

\subsection{The Relevance-Theoretic Account}

\subsubsection{Basic Relevance-Theoretic Tenets}

Relevance Theory is a cognitive pragmatic theory of language comprehension (Sperber and Wilson 1986/1995; Wilson and Sperber 1998, 2004, 2012), which has in recent years been approached empirically, experimentally, and from various points of view relating to neighbouring fields, as seen in Padilla Cruz's (2016) collection, to name one example. The cognitive characterization is due to three hypotheses assumed in this theory. Firstly, the processes implied in pragmatic interpretation are not specific to language, but are localized in the central system of thought. This hypothesis finds its roots in the theory of modularity of mind (Fodor 1983; Sperber 2005; Caruthers 2006).

\footnotetext{
${ }^{6}$ In his Model of Directional Inferences (2000a), Moeschler makes the same prediction about temporal relations between eventualities. They have an inferential nature and are drawn according to contextual assumptions. They can be blocked (minimal interpretation) under certain specific linguistic and contextual conditions.
} 
Secondly, the essential feature of human communication is the expression and recognition of intentions (Grice 1989). This hypothesis led to the suggestion of an inferential model of communication that included both the code model (as it has been believed since Aristotle that communication is achieved by coding and decoding messages) and the inferential model (as communication, according to Grice, is achieved by producing and interpreting evidence about the speaker's intended meaning). Another of Grice's central claims, recycled in Relevance Theory, is that utterances automatically create expectations that guide the hearer towards the speaker's intended meaning. Grice defines these expectations in terms of the conversation maxims and the cooperative principle. Relevance Theory adopts neither Grice's maxims nor the cooperative principle, but hypothesises that "the expectations of relevance raised by an utterance are precise and predictable enough to guide the hearer towards the speaker's meaning" (Wilson and Sperber 2004, 607).

Thirdly, the search for relevance is a basic feature of human cognition. Hence, utterances raise expectations of relevance, because the search for relevance is a basic feature of human cognition which communicators may exploit (Wilson and Sperber 2004, 607). This is expressed in the Cognitive Principle of Relevance, which states that "human cognition tends to be geared to the maximization of relevance" (Wilson and Sperber 2004, 610).

An input (a sight, a sound, an utterance, a memory) is relevant when it connects with existing or background knowledge in order to produce a positive cognitive effect-i.e. bringing new information, developing existing information or correcting existing information. These cognitive effects are positive if they help the hearer to create true representations of the world. There are numerous potentially relevant stimuli, but humans will search for the most relevant stimulus. According to Relevance Theory, in equal situations, the greater the positive cognitive effect achieved by processing an input, the greater its relevance will be. Relevance is thus weighed in terms of cognitive effects and processing efforts:

- Other things being equal, the greater the positive cognitive effect achieved by the least processing efforts, the greater the relevance of that input to the individual at that time.

According to Relevance Theory, utterance interpretation takes place via nondemonstrative inference, a process that 'takes a set of premises as input and yields as output a set of conclusions which follow logically from, or are at least warranted by, the premises' (Sperber and Wilson 1987:698), and which makes use of deductive rules without being governed by them. The premises used in the nondemonstrative process are assumptions existent in the memory. These assumptions can come from perception, linguistic decoding, encyclopedic memory, or can be added to the memory of the device as a result of the deductive process itself. Sperber and Wilson explain,

The set of assumptions in the memory of the deductive device at the start of a deductive process can be partitioned into two proper subsets, each acting as the context in which the other subset is processed. [...] We assume that a crucial step in the processing of new information is to combine it with an adequately selected set of background assumptions - which 
constitutes the context - in the memory of the deductive device. For each item of new information, many different sets of assumptions from diverse sources (long-term memory, short-term memory, perception) might be selected as context. (Sperber and Wilson 1986/1995, 137-138)

Sperber and Wilson (1998) note that what is retrieved from encyclopaedic memory and transferred to the memory of the deductive device are not individual assumptions but chunks of information (also named schemas, frames or scripts). Assimakopoulos $(2017,230)$ explains that these chunks of information "can either provide ready-made contextual assumptions or skeletal schemas (scripts), which, together with new information derived from the utterance, create fully articulated assumptions".

Given the cognitive orientation of the theory, their definition of the context, which is a key notion, is psychologically oriented:

\begin{abstract}
A psychological construct, a subset of the hearer's assumptions about the world. It is these assumptions, of course, rather than the actual state of the world, that affect the interpretation of an utterance. A context in this sense is not limited to information about the immediate phsysical environement or the immediately preceding utterances: expectations about the future, scientific hypotheses or religious beliefs, anecdotal memories, general cultural assumptions, beliefs about the mental state of the speaker, may all play a role in interpretation. (Sperber and Wilson, 1986/1995, 15-16)
\end{abstract}

Assimakopoulos (2017) points to the fact that the relevance theoretic approach to the notion of context as a cognitive construct challenges the more traditional views based on notions like common (Stalnaker 1974, 2002) or mutual knowledge (Schiffer 1972). The relevance theoretic context consists of a set of assumptions rather than true facts about the world, assumptions which are manifest to the hearer: he is capable of mentally representing them and accepting them as true at some given moment, whether they are indeed veridical (Assimakopoulos 2017). Moreover, Sperber and Wilson challenge the traditional hypothesis according to which contexts for interpretation are determined in advance of the comprehension process, and suggest that contexts are selected during the interpretation process. They adopt the view of a dynamically changing context, which is determined online via expansion of the initial context, consisting of a set of assumptions about the world originating in the memory (cf. Assimakopoulos 2017 for an extensive discussion).

One of the most basic tenets of this theory is the relevance-theoretic comprehension procedure: the hearer follows a path of least effort to find the cognitive effects needed, in order of accessibility. The interpretation process stops when the hearer's expectations of relevance are satisfied (or abandoned) (Wilson and Sperber 2004, 636), taking into consideration what is said and what is implicated (as suggested by Grice). For Grice, the explicit/implicit distinction refers to the difference between an utterance's truth-conditional and non-truth-conditional content, where the latter depends solely on pragmatics. The relevance-theoretic framework assumes quite a different position. There are two kinds of assumptions communicated by a speaker: explicatures and implicatures, defined as follows (Carston 2004, 635, citing Sperber and Wilson 1986). 
- An assumption communicated by an utterance $\mathrm{U}$ is explicit [hence an explicature] if and only if it is a development of a logical form encoded by U. [in case of ambiguity, a surface form encodes more than one logical form]

- An assumption communicated by $\mathrm{U}$ which is not explicit is implicit [hence an implicature]

Explicatures are developments of the logical form, through decoding and pragmatic enrichment, into a full propositional form of the utterance, as in (367), which is the explicature of (366). The star assigned to the word Mary indicates that a particular referent has been assigned to the name "Mary". The explicature consists of more precise and elaborated information, such as reference assignment, the narrowing of the concepts get and unit, the enrichment of the meaning of words like enough, and adding the cause-consequence relation between the two segments. ${ }^{7}$ On the other hand, sentence (368) is an independent assumption inferred as a whole from (367), and a further premise concerning the relation between Mary's recent failure at university and her current state of mind (Carston 2004).

\section{$\mathrm{X}$ : How is Mary feeling after her first year at university?}

Y: She didn't get enough units and can't continue.

Mary* did not pass enough university course units to qualify

for admission to second-year study, and as a result, Mary* cannot continue with university study.

Mary* is not feeling very happy.

According to Relevance Theory, the relevance-theoretic interpretative procedure consists of several subtasks that take place in parallel. The logical form encoded by an utterance containing incomplete conceptual representations is treated in the inferential process in three ways (Wilson and Sperber 2004, 615):

- Constructing an appropriate hypothesis about the explicit content (explicatures) via decoding, disambiguation, reference resolution and other pragmatic enrichment processes (narrowing, loosening, saturation, free enrichment, ad hoc concept construction $\left.{ }^{8}\right)$

\footnotetext{
${ }^{7}$ This is an important point of divergence between relevance theorist and neo-Gricean pragmatic frameworks. Neo-Griceans have followed Grice in considering these aspects of communicated meaning to be implicatures (see Carston 2004, sections 4-6).

${ }^{8}$ Carston (2004) discusses the pragmatic aspects of explicatures (the pragmatically determined aspect of what is said). Disambiguation concerns the selection of sense for polysemantic words (such as bank), the candidates being supplied by the linguistic system itself. Reference resolution concerns referent assignment to deictics, overt indexicals and referential expressions. Saturation concerns pragmatic developments of the logical form required by covert indexicals (such as better, same, too, enough), and is under linguistic control. Free enrichment is not triggered by a linguistic expression, and concerns aspects of the interpretation of the utterance that are relevant for the implicatures. The utterance I've had a shower contains the idea of today, that comes through free enrichment, and is considered in the implicature I don't need to have another shower now/today. In neo-Gricean pragmatics, these aspects of utterance meaning are generalized conversational implicatures.
} 
- Constructing an appropriate hypothesis about the intended contextual assumptions (implicated premises)

- Constructing an appropriate hypothesis about the intended contextual implications (implicated conclusions)

Wilson and Sperber point that there is no sequential order in which these subtasks of the comprehension process take place, due to the fact that comprehension is an online process. They take place in parallel and the resulting hypotheses are, if necessary, revised or elaborated as the utterance unfolds. Thus, explicatures and implicatures (consisting of implicit premises and conclusions) are constructed by a process of "mutual parallel adjustment with hypotheses about both being considered in order of accessibility" (Wilson and Sperber 2004, 617).

At this point, I would like to have a closer look at explicatures. Explicatures roughly correspond to Grice's category of generalized conversational implicatures and to Levinson's (2000) informational amplifications of utterances. They are enriched forms of the propositional form, and are truth-conditional: an explicature is true or false iff the proposition expressed by the utterance is true or false (Sperber and Wilson 1986; Wilson and Sperber 2004; Cartson 2002). The main idea is that a proposition cannot be true when its explicature is false, and the explicature cannot be true when the proposition is false.

Explicatures, contrary to other forms of implicit meaning such as entailments and presuppositions, can be made explicit (Moeschler 2013). This happens either in the form of basic explicatures, as in (370), which enriches (369) with a temporal variable, or in the form of higher-order explicatures as in (371).

(369) It's raining.

(370) It's raining, I mean, right now.

(371) Can you take down the garbage? It's not a question; it's an order.

The most convincing example of phenomena taking place at the level of explicature is given by the lexical-pragmatic processes involved in the construction of adhoc concepts: narrowing and loosening. However, other phenomena have gradually been considered as taking place at the level of explicatures. For example, the contrast interpretation of the discourse connective but, which was treated as conventional implicature by Grice, is analysed by Blakemore (1987) and followers as procedural encoding, constraining the comprehension process. More recently, in relation to connectives, Moeschler $(2015,2016)$ suggests that conceptual meaning is associated with logical entailments, whereas procedural information is activated at two levels: explicatures (and therefore truth-conditional) and implicatures (and therefore non-truth-conditional).

Wilson and Sperber $(2004,613)$ point to the fact that, due to the presumption of optimal relevance given below, it is reasonable for the hearer to follow the path of least effort, because the speaker is expected (within the limits of her abilities and preferences) to make her utterance as easy as possible to understand. 
The ostensive stimulus is relevant enough to be worth the audience's processing effort. It is the most relevant compatible with communicator's abilities and preferences. (Wilson and Sperber 2004, 612).

This idea was honed by the conceptual/procedural distinction (Blakemore 1987; Wilson and Sperber 1993; cf. discussion in Sect. 2.3.2). Since a speaker is not expected to make her addressee's task of obtaining the most relevant interpretation more difficult than necessary, the utterance she chooses to formulate may contain conceptual and procedural types of information. Therefore, procedural meanings are instructions encoded by linguistic expressions that specify paths to follow during the comprehension procedure, which involves manipulating conceptual representations. Wilson and Sperber (1993, 151) argue that conceptually encoded information contributes either to explicatures (the proposition expressed and higherlevel explicatures) or to implicatures (see Nicolle 1998 for arguments against this option), whereas procedurally encoded information limits the formulation of either explicatures (the proposition expressed and high-level explicatures) or implicatures.

\subsubsection{The Conceptual/Procedural Distinction}

One of the proposals made by Relevance Theory, aiming to explain how specific linguistic items contribute to the inferential processes involved in utterance interpretation, is the replacement of the speech act theoretic distinction between describing and indicating with the cognitive distinction between conceptual and procedural types of encoded meaning (Blakemore 1987, 2002; Wilson and Sperber 1993). ${ }^{9}$ Procedural meaning points to encoded instructions about how to manipulate conceptual representations. Both the concept and the linguistic expression are stored in the lexicon, where procedural information is embodied as rules written explicitly in the lexical entries of linguistic expressions (Curcó 2011). For relevance-theorists, a speaker is not expected to make her addressee's task of obtaining a relevant interpretation more difficult than necessary. Therefore, procedural meanings are instructions encoded by linguistic expressions that specify paths to follow during the interpretation process, involving the manipulation of conceptual representations in order to access the most relevant context.

The conceptual/procedural distinction was first meant as a solution for the semantic/pragmatic division of labour, and has remained a significant explanation for the contribution of linguistic meaning to utterance interpretation. Over the last 20 years, there has been growing interest in establishing discriminatory features of procedural rather than conceptual information, and in applying the distinction to

\footnotetext{
${ }^{9}$ In the French literature, a very influential work was that of Ducrot (notably Ascombre and Ducrot 1983), who suggested similar ideas in the framework of argumentation and polyphony. Ducrot spoke about instructional expressions (such as puisque 'since' and mais 'but'), and his model aimed to model their argumentative function.
} 
Table 2.1 Cognitive and linguistic features

\begin{tabular}{l|l}
\hline Cognitive criteria & Linguistic criteria \\
\hline 1. Representational status & 1. Truth-value \\
\hline 2. Accessibility to consciousness & 2. Behaviour with negation \\
\hline \multirow{2}{*}{ 3. Degree of availability to conscious thought } & 3. Compositionality \\
\cline { 2 - 2 } & 4. Rigidity \\
\hline \multirow{2}{*}{ 4. Degree of conceptualization } & 5. Degree of paraphrasability \\
\cline { 2 - 2 } & 6. Behaviour with loosening and narrowing \\
\cline { 2 - 2 } & 7. Type of inference triggered \\
\hline
\end{tabular}

various linguistic expressions_-for example, Escandell-Vidal et al.'s (2011) collective volume, Sassamoto and Wilson's (2016) special issue, and Grisot (2017a), to name but a few. Numerous attempts have been made in the literature to define and characterize conceptual vs. procedural information, including qualitative features. In Grisot (2017a), I divide them into two types: those that are cognitive (appealing to cognitive processes taking place when the speaker processes expressions encoding conceptual or procedural types of information); and those that are linguistic (referring to the linguistic system itself). The two types of criteria summarized in Table 2.1 are challenged in Grisot (2017a), where I put forward a quantitative approach to conceptual, procedural and purely pragmatic meaning.

The first attempts to define and characterize conceptual vs. procedural information included qualitative features such as representational vs. computational and truth-conditional vs. non-truth-conditional. One very significant contribution to the discussion is Wilson and Sperber (1993) hypothesis of the cognitive foundations of the distinction. They characterize conceptual vs. procedural information in terms of accessibility to consciousness vs. inaccessibility to consciousness, easily graspable concepts vs. information resistant to conceptualization, and information capable of being reflected on vs. information not available through conscious thought (Wilson and Sperber 1993, Wilson 2011). These features of conceptual and procedural information not only find their roots in the parallel that has been made between natural language and the 'language of thought', but also in the 'massive modularity hypothesis' (Sperber 2005; Carruthers 2006). Sperber and Wilson (1998, 172-173) suggest that the constituents of a language are systematically related to other objects, such as constituents of other language, with states of language users, or with possible states of the world. Based on these remarks, Wilson $(2011,10)$ indicates that:

- Conceptual expressions in natural language are systemically linked to concepts, which are constituents of language of thought;

- Procedural expressions in natural language are systematically linked to states of language users;

- Sentences of the language of thought are systematically linked to possible states of the world.

Wilson argues that, according to the second hypothesis, procedural expressions have the function of putting the language user into a state in which some of these 
domain-specific cognitive procedures are highly activated $(2011,11)$. The output of the highly activated procedures functions as ostensive cues, more likely to be selected by the hearer during the comprehension process. In Wilson's words, expressions like dog or think encode conceptual representations (constituents of language of thought), accessible to consciousness and capable of being reflected on, evaluated and used in general inference. By contrast, procedural expressions such as but and $o r$ activate domain-specific procedures belonging to fodor-modules (encapsulated and inaccessible), and are inaccessible to consciousness and resistant to conceptualization.

The main idea is that, during the interpretation process, the hearer builds conceptual representations and uses encoded procedures for manipulating them. A conceptual representation differs from other types of representations in that it has logical properties and truth-conditional properties. The sentence in (372) has the logical form (373) and the propositional form (374). Wilson and Sperber (1993) argue that the logical form recovered by decoding and the propositional form recovered by a combination of decoding and inference are conceptual representations.

(372) Peter told Mary that he was tired.

(373) $\mathrm{x}$ told $\mathrm{y}$ at $\mathrm{t}_{\mathrm{i}}$ that $\mathrm{z}$ was tired at $\mathrm{t}_{\mathrm{i} .}$

(374) Peter Brown told Mary Green at 3.00 pm on June 231992 that Peter Brown was tired at $3.00 \mathrm{pm}$ on June 231992.

As far as procedural information is concerned, Wilson and Sperber (1993) argue that it represents constraints on the inferential phase of comprehension, as in example (375), which can be interpreted as in (376) and in (377). Quoting Blakemore $(1987,1992)$, Wilson and Sperber $(1993,158)$ note that the connectives so and after all do not contribute to the truth conditions of the utterances, but constrain the inferential phase of comprehension by indicating the type of inference the hearer is expected to make.

(375) Peter's not stupid. He can find his own way home.

(376) Peter's not stupid; so he can find his own way home.

(377) Peter's not stupid; after all he can find his own way home.

It seems that the key idea in distinguishing the two types of information is the notion of the contribution to (conceptual) or constraining of (procedural) the construction of explicatures and implicatures. Unfortunately, these two notions are quite vague, and cannot easily be used as discriminating criteria. An initial attempt has been made to use the contributing/constraining distinction in relation to the truth-conditional evaluation of a proposition. But the picture is not black and white: Wilson and Sperber (1993) distinguish four possible combinations: (a) conceptual and truth-conditional (most regular content words, such as manner adverbials seriously and frankly); (b) conceptual and non-truth-conditional (illocutionary adverbials such as seriously, frankly, unfortunately); (c) procedural and non-truth-conditional (discourse connectives like $s o$ and after all); and (d) procedural and truth-conditional 
(such as personal pronouns $I$ and you). Discourse connectives constrain the construction of implicatures by guiding the search for intended contexts and contextual effects. Pronouns impose constraints on explicatures by guiding the search for the intended referent relating to the proposition expressed. As far as conceptual information is concerned, it may or may not contribute to the truth-conditions of the proposition expressed. Explicatures can, however, have their own truth-conditions (be false or true), and can therefore be contradicted, negated and used in entailment.

Another attempt to explain the contributing and constraining notions was to explain them in relation to their function in determining the intended inferences. De Saussure (2011, 61-62) points out that procedural expressions encode specific paths to follow in order to obtain specific inferences. The first consequence is that it is not impossible for the hearer to get to the intended inference in the absence of the procedural expression, but this would happen (though is not guaranteed) at a higher cognitive cost. The second consequence is that there are also more general inferences that are not specifically encoded by linguistic expressions. This is the case of inferences obtained by general means of pragmatic reasoning starting from conceptual-encyclopaedic information. For de Saussure, procedural information encoded by expressions such as but (Blakemore 1987) linking two propositions $\mathrm{P}$ and Q excludes a variety of possible inferences that can hold between two P and Q, and guides the hearer toward the intended specific inference. It is in this way that procedural information constrains the inferential phase of communication, and achieves better relevance by eliminating the unintended potential interpretations. Conceptual information, on the other hand, through the rich encyclopaedic entries opens up a large array of possible assumptions, therefore contributing to the inferred premises and conclusions achieved by general inference. While this account of the contribute/constrain division is interesting from a theoretical point of view, it is limited to use as a discriminating criterion.

De Saussure (2011) proposes a methodological criterion to distinguish between what is conceptual and what is procedural. In his words, an expression is procedural as it triggers inferences that cannot be predicted on the basis of a conceptual core to which general pragmatic inferences (loosening and narrowing) are applied. In his view, expressions that encode (at least apparently) both procedural and conceptual information (such as third personal pronouns, verbal tenses and some French pragmatic connectives such as ensuite 'then') should be considered procedural. He argues that procedural information:

... either takes conceptual information as a parameter as with she, and therefore the conceptual information is simply under the dependence of the procedure, or the conceptual meaning has no motivation anymore and is just a relic of ancient versions of that word (the case of ensuite) (p. 65, original italics).

Escandell-Vidal and Leonetti (2011) propose that rigidity is the major feature of procedural information. Their hypothesis is that conceptual information is flexible, while procedural information is rigid. 
...Conceptual representations are flexible and malleable, which means that they can be enriched, elaborated on and adjusted in different ways to meet the expectations of relevance. (...) We claim that instructions, in contrast, are rigid: they cannot enter into the mutual adjustment process, nor can they be modulated to comply with the requirements of conceptual representations, either linguistically communicated or not. The instructions encoded by an item must be satisfied at any cost for the interpretation to succeed. (EscandellVidal and Leonetti 2011, 86)

This idea was also suggested for French markers expressing temporality by Moeschler (2000a), who argued that procedural information, e.g. encoded by temporal connectives, is stronger than conceptual information, e.g. encoded by aspectual classes (i.e. Aktionsart).

Escandell-Vidal and Leonetti argue that, despite their rigid character, instructions can give rise to a series of different interpretative effects. This is due to the different contextual assumptions, and data varying from one context to another. The main consequence is that cases of mismatch between the information from conceptual and procedural content will be solved by following the procedural constraints on interpretation. Escandell-Vidal and Leonetti (2011, 84-85) suggest a series of theoretical assumptions about procedural information, as follows:

- Instructions are operational: they specify a set of algorithms or logical operations.

- Instructions operate on conceptual representations.

- Instructions can operate at two different levels: that of syntactic computation and that of interpretation.

- Linguistic items can encode concepts and instructions. Conceptual representations are linked to encyclopaedic knowledge, but instructional meanings lack such connections.

- A strong connection was initially established between the lexical vs. functional (i.e. grammatical) distinction and the conceptual/procedural distinction. Recent work suggests, however, that functional words can also encode conceptual information (such as connectives, as suggested by Blochowiak 2015a, b, 2017, and verbal tenses, as suggested by Grisot and Moeschler 2014 and Grisot 2017a).

The classic view of the conceptual vs. procedural distinction assumes that there is a clear-cut distinction between what is conceptual and what is procedural. This has led to the assumption that there is perfect mapping between conceptual/procedural information and lexical vs. grammatical categories. It was assumed that lexical categories (nouns, verbs, adjectives bearing descriptive content, -ly adverbs) encode concepts, whereas grammatical or functional categories encode various kinds of constraints on inferential processes. Several scholars have argued against this assumption, showing that a single expression can encode both procedural and conceptual meaning. The prototypical expressions encoding a concept are lexical words, such as door, bachelor, open, etc. These entries in the mental lexicon are used to refer to sets of entities (the sets of entities which are doors, bachelors, and actions of opening things, respectively). However, as Moeschler $(2016,126)$ points out, "a concept is not only a mental representation of different sets of individuals, it 
is the abstract or mental entity that allows the fixation of beliefs and knowledge: concepts are the locus of information construction, storage and retrieval." According to this definition of a concept, both lexical and functional categories (such as verbal tenses and connectives) may encode conceptual meaning. This proposal defends a dual and hybrid nature of linguistic expressions: conceptual and procedural encoding.

So, it could be the case that third person pronouns (he, she) not only encode the instruction to identify a highly accessible referent (Ariel 1994) but also include some conceptual information about the referent, such as male/female and animate (Escandell-Vidal et al. 2011, 24). Hence, the accessibility requirement is common for the whole class of third person pronouns, whilst the conceptual information varies from pronoun to pronoun. For example, the case of the pronoun it remains problematic for this approach, because it can refer both to objects and animate beings, without discriminating gender, as with dog or baby. Moreover, the gender distinction refers to grammatical gender and not to actual gender, as illustrated by the cross-linguistic difference between the people in English and la gente (feminine) in Italian. For Moeschler (2015), connectives are complex linguistic units conveying both conceptual and procedural information. His analysis of close connectives in French (parce que 'because', donc 'therefore' and et 'and') illustrates that they have conceptual and procedural content, with both types triggering different levels of meaning. They all share causal conceptual content, even though the set of entailments are not identical: $\mathrm{P}$ and $\mathrm{Q}$ for parce que and et, and only $\mathrm{P}$ for donc. Moreover, the causal meaning is an explicature (not defeasible) with parce que, and an implicature (defeasible) with et and donc.

For Wilson $(2011,10)$, conceptual expressions in natural language are systematically linked to concepts, which are constituents of the language of thought. In their earlier work, Sperber and Wilson (1998) described the relevance theoretic account of the mapping between the mental and the public lexicon. They assumed that mental representations consist of mental concepts, which are relatively stable units. A mental concept encompasses causal and formal (semantic or logical) relationships with external objects (i.e. words in a language) and relationships with other mental concepts. Sperber and Wilson (1998) argue against a one-to-one mapping between words in a language and mental concepts. Consequently, there may be:

- Concepts for which there is no word in a given language (one might expect that some languages do express them, or they can be expressed by means of a phrase) (none-to-one).

- Words lacking a conceptual counterpart (one-to-none), such as 3rd personal pronouns.

- Different words that correspond to one concept (many-to-one), such as synonyms.

- A word corresponding to several concepts (one-to-many), such as homonyms.

The lack of one-to-one mapping can be explained by the existence of words in a language relating to all grammatical categories that do not encode a 'full-fledged concept but what might be called a pro-concept. The semantic contribution of pro- 
concepts must be contextually specified for the associated utterance to have a truthvalue' (Sperber and Wilson 1998, 184). The authors make the claim that pro-concepts are so common that 'all words behave as if they encoded pro-concepts' (Sperber and Wilson 1998, 185). This is due to the fact that their semantic meaning must be worked out contextually-i.e. fine-tuned through inferential processes so as to create an ad hoc concept (Barsalou 1987, Carston 2002; Wilson and Carston 2007).

Ad hoc concept construction concerns the pragmatic adjustment of the concepts encoded in the utterance. The utterance He was upset but he was not upset, said by the defence lawyer of a man who murdered his wife, is not a contradiction. The hearer understands that the man was upset, but not upset to the point that he might kill his wife. The two interpretations of upset correspond to two concepts of upsetness resulting from a narrowing of the ad hoc concept UPSET. This view of concepts was initially adopted for 'open' classes of words (nouns, verbs, adverbs and verbs), as in example (378), from Wilson and Carston (2007, 235), where the hearer is prompted to build a fine-tuned ad hoc concept drinking alcohol by way of lexical narrowing (i.e. the word conveys a more specific sense than the encoded one). Another means of contextual adjustment is lexical broadening, ${ }^{10}$ involving the use of a word to convey a more general sense that the encoded one, as in (379), from Wilson and Carston $(2007,235)$.

I am not drinking tonight.

That bottle is empty.

The hearer makes hypotheses about this type of content at the level of explicatures (i.e. truth-conditional content). This occurs mainly because:

The meaning encoded in a linguistic expression underdetermines the content the speaker communicates, not only at the level of her implicatures but also the propositional content she communicates explicitly (i.e. the explicature of the utterance) (Carston 2010, 156).

So, during communication, the addressee's task is to identify the speaker's informative intention - that is, the content she wants to transmit, along with her communicative intention (Sperber \& Wilson 1986/1995). To do so, the addressee has to accomplish a series of sub-tasks, determining the logical form of the speaker's utterance (by decoding), the propositional form (by inference) or (first level) explicature, the speaker's propositional attitude or high-level explicature, and the most relevant implicature of the speaker's utterance. Conceptual, procedural and pragmatic meanings play a role in performing these sub-tasks. Procedural meaning, encoded by specific linguistic items, triggers specific inferences which constrain this interpreta-

\footnotetext{
${ }^{10}$ According to Wilson and Carston (2007), there are several types of broadening, namely approximation, hyperbolic extension, metaphorical extension and category extension (e.g. the use of salient brand names for a broader category), among others. Narrowing and broadening make use of the encyclopaedic properties of a concept, where at least one property is shared between the pro-concept and the ad hoc concept. The enrichment process is carried out using the encyclopaedic properties of the concept, contextual information, pragmatic expectations, and principles of relevance.
} 
tive inferential process, whereas conceptual information is treated at the level of the explicatures of the utterance by way of pragmatic enrichment processes like narrowing and broadening, linked to the concept which they encode. Pragmatic interpretations are recovered by general inferences, rather than triggered by linguistic expressions, and depend on the contextual hypotheses that the hearer formulates. Therefore, they can be localized at the level of implicatures. In Grisot (2017a), I propose a quantitative approach guarantees that the investigation of each level in the inferential interpretative process is valid and reliable: the pragmatic adjustment of conceptual meaning by narrowing and broadening; the specific inferential paths signalled by expressions encoding procedural information; and general inferences (i.e. implicated conclusions formulated according to implicated premises and the propositional form of the utterance) (Sect. 4.1).

\subsubsection{Verbal Tenses as Procedural Expressions: Reichenbachian Coordinates}

As far as temporal reference is concerned, in the relevance theoretic framework, it is generally assumed that verbal tenses are fully procedural expressions. From this perspective, verbal tenses encode only procedural information. Two approaches can be distinguished. According to the first, procedural meaning mainly concerns the saturation of Reichenbachian coordinates for locating eventualities in time (Nicole 1997; de Saussure 2003, 2011; Escandell-Vidal and Leonetti 2011; Aménos-Pons 2011). According to the second, procedural meaning is linked to the expression of temporal relations between eventualities: it guides "directional" forward and backward inferences in Moeschler's terms (2000a).

The discussion of verbal tenses involves their function of establishing temporal reference by the positions of temporal coordinates (speech point $S$, reference point $\mathrm{R}$ and event point $\mathrm{E}$ ) and determining the temporal sequencing of eventualities. De Saussure (2011) suggested that a verbal tense is a procedural marker, in that it specifies the computations that should be made with hearer's mental representations of eventualities. The output of the computation is a contextual value in the form of an inference. The procedure encoded by a verbal tense demands that the hearer find the configuration of temporal coordinates $\mathrm{S}, \mathrm{R}$ and $\mathrm{E}$ which is most relevant and consistent with contextual assumptions, in order to locate an eventuality before, at the same time as, or after $\mathrm{S}$.

The main relevance-theoretic assumption regarding tense markers is that the meaning of a verbal tense is underdetermined. Consequently, to yield the speaker's intended meaning, a verbal tense must always be contextually enriched by inference in accordance with the principles of relevance. N. Smith (1990) points out that a verbal tense can only locate temporal reference in an underspecified way. Establishing actual temporal reference takes place by way of contextual enrichment, according to expectations of optimal relevance. Smith's assumption was that the 
various connotations associated with a verbal tense correspond not to different meanings of that tense, but to different interpretations of a unique meaning combined with various contextual assumptions.

Nicolle (1998) followed Smith's assumption, and proposed that tense marking is procedural information. In his words,

Tense markers, in those languages which have them, may be characterized as merely imposing constraints on the determination of temporal reference. Similarly, markers of modality may be viewed as encoding constraints on the existential status of situations and events. Conversely, it is difficult to see how markers of tense and modality could be characterized conceptually. Take for instance, example (1) [Mary has eaten] and (2) [Mary has climbed Everest]; the "present perfect" does not encode information about itself but about the events described in (1) and (2), say, that the event [Mary eat] and [Mary climb Everest] are meant to be represented as occurring at some time in the past whilst having present relevance. As a result of these considerations, grammatical markers of tense and modality may be characterized as exponents of procedural encoding, constraining the inferential processing of conceptual representations of situations and events.

The first relevance-theoretic analyses of French verbal tenses expressing past time pointed to the fact that they have inferential descriptive and interpretative usages, computed according to the instructions encoded by a verbal tense, and to contextual information (Moeschler et al. 1998; Luscher and Sthioul 1996; Luscher 1998, Sthioul 1998; de Saussure and Sthioul 1999, 2005; Tahara 2000; de Saussure 2003). Descriptive usages of the Passé Simple are outlined in terms of a basic semantic framework using Reichenbachian coordinates $\mathrm{E}, \mathrm{R}$ and $\mathrm{S}$ - or, more precisely, $\mathrm{E}=\mathrm{R}<\mathrm{S}$. This description corresponds to the procedural information encoded by the Passé Simple, which is to locate the eventuality before $\mathrm{S}$ via an $\mathrm{R}$ which is simultaneous with E. The temporal localization of an eventuality must therefore be calculated contextually, and this is an inferential process. Following de Saussure (2003), I will from now on call this trend the procedural pragmatics approach.

De Saussure's proposal is that the interpretation process is an algorithmic procedure. As far as temporal interpretation is concerned, verbal tenses play an important role, in that they set the temporal reference of eventualities in relation to the moment of speech. In his words $(2003,179)$ :

La référence temporelle correspond au moment du temps, dans la conscience du destinataire, pour lequel les conditions de vérité du procès décrit sont vérifiées. Il est vraisemblable que l'esprit applique une stratégie aspectuelle pour se représenter les événements. ${ }^{11}$

For example, to process the sentences in (380) and (381), from de Saussure (2003, 179), the hearer does not determine a temporal interval lasting from a few seconds in the former to a few hours in the latter, but a punctual and bounded cognitive representation of the eventuality. This is mainly due to the assumption that the Passé Simple is a perfective verbal tense.

\footnotetext{
11 'Temporal reference corresponds to a moment in time when, for the hearer, the truth-conditions of the eventuality are verified. It is possible that the human brain applies an aspectual strategy for cognitively representing events.' (my translation)
} 
(380) La bombe explosa.

'The bomb exploded.'

(381) Frédéric et Marie-Hélène emplirent la piscine.

'Frédéric and Marie-Hélène filled the pool.'

As for the second sentence in (382), containing a telic eventuality (i.e. accomplishment), the hearer builds an unbounded cognitive representation due to the Imparfait. De Saussure argues that the Imparfait imposes an imperfective reading of eventualities, regardless of their type (state, activity, accomplishment or achievement).

(382) Luc arriva au stade. Augustin courait le 1500 mètres.

Luc arrive.PS at the stadium. Augustin run.IMP the 1500 meters

'Luc arrived at the stadium. Augustin was running the 1500 meters.'

More generally, temporal reference is an important factor for determining the temporal sequencing of eventualities in the discourse. For de Saussure, temporal order consists of three types of temporal relations: positive (i.e. forward sequencing), negative (i.e. backward) and null (i.e. simultaneity and indeterminacy). Temporal sequencing is the result of an algorithm, which consists of a general procedure and specific procedures. Procedural markers, such as verbal tenses and temporal connectives, trigger specific procedures taking place in the interpretation process. Moreover, conceptual relations (such as push-fall) and procedural markers impose constraints on determining the temporal sequencing of eventualities.

As for the analysis of specific verbal tenses, de Saussure $(2003,222)$ argues that the Passé Simple encodes an instruction for temporal progression by default. This instruction is blocked when the hearer does not have sufficient contextual information to interpret the utterance, as in (383), and in cases of temporal encapsulation, as in (384) and (385), from de Saussure (1998b, 249).

(383) François épousa Adèle. Paul s'acheta une maison à la campagne. 'François married Adele. Paul bought a house in the countryside.'

(384) Une terrible tempête fit rage. Quelques tuiles tombèrent. Un arbre du jardin fut arraché.

'A terrible storm raged. Some tiles fell. A tree was torn from the garden.'

(385) Ce samedi marqua le début de la relation de Paul et Marie.

Ils déjeunèrent ensemble. Ils se promenèrent sur les berges.

Le soir, ils s'embrassèrent pour la première fois.

'That Saturday marked the beginning of Paul and Mary's relation.

They had lunch together. They went for a walk on the riverbank.

In the evening, they kissed for the first time.'

The Passé Simple may occur in contexts with backward temporal sequencing, but only accompanied by an appropriate connective, such as dès que 'as soon as', as 


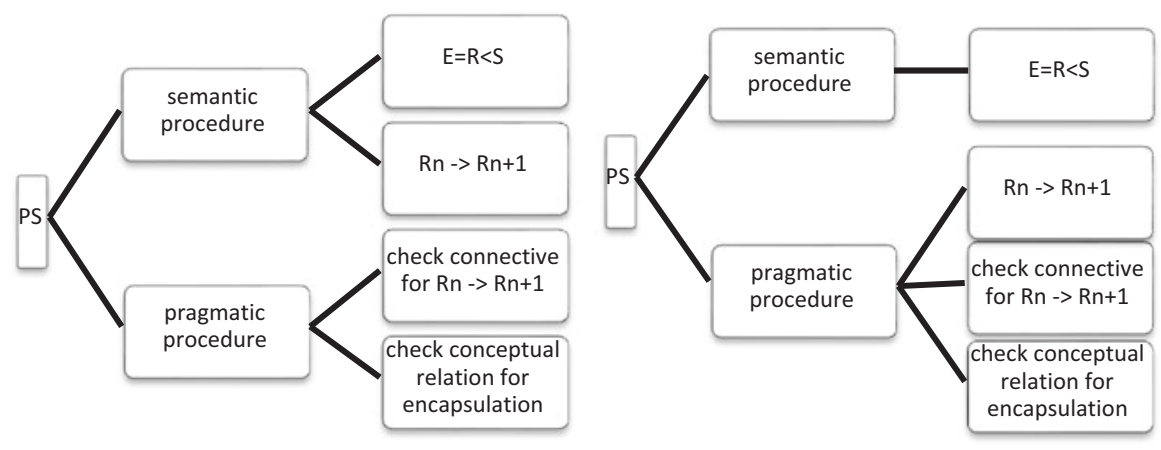

Fig. 2.1 Interpretation of the Passé Simple: Version 1 and 2

shown in examples (386) and (387), from de Saussure (2003, 223). Without the connective, the Passé Simple imposes temporal progression (i.e. the convicted fainted before the reading of the sentence).

(386) Le condamné s'évanouit dès que le juge lut la sentence.

'The convicted fainted as soon as the judge read the sentence.'

(387) Le condamné s'évanouit. Le juge lut la sentence.

'The convicted fainted. The judge read the sentence.'

Consequently, de Saussure proposes two possible descriptions of the semantics and the pragmatics of the Passé Simple (de Saussure 2003, 228), which are interpretative procedures. ${ }^{12}$ In version 1, on the left-hand side of Fig. 2.1, there are two semantic procedures specific to the Passé Simple (i.e. to locate $\mathrm{E}$ before $\mathrm{S}$ via an $\mathrm{R}$ simultaneous to $\mathrm{E}$, and to increment $\mathrm{R}$ if possible, marking temporal progression) and two pragmatic procedures (i.e. if there is a connective or a conceptual relation requiring backward temporal progression, allow it). However, hearers apply the default procedures unless they are blocked by the contextual information regarding the connectives and conceptual rules. Version 2, on the right-hand side of Fig. 2.1, is based on the argument that the value of $\mathrm{R}$ must be computed contextually; hence, in this version, this step is independent independent of the semantic procedure and is included in the pragmatic interpretation, which therefore includes three steps.

Taking the same procedural pragmatics approach, Sthioul (1998), Tahara (2000) and de Saussure (2003) discuss descriptive and interpretative usages of the Passé Simple. In Relevance Theory, utterances point to world representations-i.e. they represent hypotheses, thoughts, beliefs, etc. about the world (or the fictional world of a novel). In this case, utterances are used descriptively. There are also cases when an utterance is used to represent the thought or belief of third party at odds with the speaker's at the moment of speech S. In this case, utterances are used subjectively (de Saussure 2003, 130). As far as verbal tenses are concerned, de Saussure argues

${ }^{12}$ For the exact algorithm to follow, see de Saussure (2003, 228). 
Table 2.2 Descriptive and interpretative usages of the Passé Simple

\begin{tabular}{l|l}
\hline Descriptive usages of Passé Simple & Interpretative usages of Passé Simple \\
\hline Perfective & Inchoative or Perfective \\
\hline$E=R<S$ & $E=R<S$ \\
\hline$R_{n}->R_{n+1}$ & $R_{n}->R_{n-1}$ or $R_{n+1}$ \\
\hline Neutral perspective & Subjective perspective \\
\hline Emphasized information & Emphasized information \\
\hline
\end{tabular}

that semantic and pragmatic temporal procedures, combined with contextual assumptions, may trigger interpretative usages. According to Tahara (2000), the Passé Simple has descriptive and interpretative usages, which present the features provided in Table 2.2 .

Descriptive usages correspond to the classical description of the Passé Simple. As for interpretative usages, the Passé Simple can be inchoative, as in (388) and (389), from Sthioul (1998, 217 and 218). The interpretative Passé Simple can also be perfective, providing instructions for backward temporal sequencing, as in example (390), from Vuillaume (1990, 10). In all these examples, the Passé Simple presents the situation from a subjective perspective, identified by the hearer, based on contextual assumptions (i.e. the moment when Paul perceives the cold in the first example, and sees the monster in the second example, and the moment signalled by the temporal deictic today, corresponding to the character's-not the speaker'stoday, in the third example).

(388) Paul sortit. Dehors, il fit bigrement froid.

'Paul went out. Outside, it was fantastically cold.'

(389) Paul leva les yeux. Un monstre se tint devant lui.

'Paul looked up. A monster was standing in front of him.'

(390) Le malheur diminue l'esprit. Notre héros eut la gaucherie de s'arrêter auprès de cette petite chaise de paille, qui jadis avait été le témoin de triomphes si brillants. Aujourd'hui personne ne lui adressa la parole; sa présence était comme inaperçue et pire encore.

(Stendhal H. de., Le rouge et le noir).

'Misfortune lessens the spirit. Our hero had the clumsiness to stop next to this small straw chair, which was long ago the witness of such brilliant triumphs. Today nobody talked to him, as though his presence were unnoticed, or even worse.'

According to the procedural pragmatics approach, de Saussure (2003) (also de Saussure and Sthioul 2005) systemized these observations and proposed a general procedure for the interpretation of the Imparfait. Based on previous work (de Saussure and Sthioul 1999), he argued that the Imparfait instructs the hearer to build an unsaturated $P$ variable interior to the event, which will be saturated contextually either by the reference moment $\mathrm{R}$ (corresponding to descriptive usages of the Imparfait) or by a moment of consciousness $\mathrm{C}$ (corresponding to interpretative 
usages of the Imparfait). It is thus in the process of assigning temporal reference that the hearer builds a subjective perspective of the situation.

In his analysis of the narrative Imparfait, de Saussure suggested that it occurs when the hearer infers, from contextual information, either achievement implicatures (blocked in the descriptive usages of the Imparfait) or forward/backward temporal sequencing, as in (391) and (392) respectively. He emphasizes that the narrative Imparfait is not interchangeable with the Passé Simple because it provides a view of the event from the interior, whereas the Passé Simple views the process as a whole. In (391), the adverb déjà ('already') suggests the speaker's subjective perception of the situation from the interior, and occurs with the narrative Imparfait. The same utterance is not acceptable with the Passé Simple, as in (393), which imposes a view from the exterior.

(391) Le train quitta Londres. Une heure plus tard, il entrait déjà en gare de Birmingham. (Sthioul 1998, 213)

The train left London. One hour later, it enter.3SG.IMP already in Birmingham station.'

'The train left London. One hour later, it was already entering Birmingham station.'

(392) Judith ne reconnut pas le "joyeux colporteur" qui la quittait quelques semaines plutôt. Klum $(1961,258)$

Judith did not recognize the "happy peddler" who her leave.3SG.IMP three weeks before.

'Judith did not recognize the "happy peddler" who broke up with her three weeks before.'

(393) Le train quitta Londres. Une heure plus tard, il entra ?déjà en gare de Birmingham.

'The train left London. One hour later, it enter.3SG.PS already in Birmingham station.'

De Saussure $(2011,2013)$ explored cases when tenses do not refer to time, or refer to points in time other than those referred to in most cases. To be more precise, he pays special attention to narrative and background uses of the Imparfait, and future time reference with the Passé Composé, among others. According to de Saussure's $(2011,67)$ methodological criterion for distinguishing between conceptual and procedural information, these distinctive possible interpretations cannot be accounted for, unless they are written into the verbal tense's procedure. In other words, there are no identifiable conceptual cores of the Imparfait and Passé Composé that can predict their distinctive interpretations. According to de Saussure, there are three aspects that contribute to distinctive interpretations of certain verbal tenses:

- Constraining contextual assumptions

- Contextual saturation of temporal coordinates R and S

- Communicative principle of relevance 
The Imparfait in (394) and (395) changes its behaviour (similar to the English progressive, except that it doesn't imply dynamicity) under the contextual constraints of boundedness and temporal sequencing in (394), by virtue of relevance. The third party subjective perspective of the eventuality, the C-point, as in (391), is a semantic procedural constraint. Since the sentence carries the presumption of its own relevance, its interpretation must be consistent with the pertaining contextual assumptions. And this happens by a pragmatic modulation of the temporal interpretation associated with the Imparfait. The situation is similar for the interpretation of the Passé Composé in (395), where the representation of the eventuality is pragmatically shifted into the future, from where it is conceived of as past. This shift occurs due to the future temporal adverbial positioning the projected point $\mathrm{R}$ corresponding to a third party's viewpoint.

(394) A huit heures, Marie trouvait ses clés et sortait. At eight, Mary find.3SG.IMP her keys and get out.3SG.IMP

'At eight, Mary found her keys and left.'

(395) Dans un an, j'ai fini avec cette dette.

In a year, I finish.1SG.PC with this debt

'In a year, I will have finished with this debt.'

Another example of the procedural nature of tense markers is that of the analysis of the simple and compound past forms in Spanish. Aménos-Pons (2011) accounts for the distinctive possible interpretations of the Spanish compound past (resultative, existential, universal, hodiernal past and hot news, illustrated in examples (396)-(400)) in terms of its procedural content (Aménos-Pons 2011, 241).

(396) Los precios han subido mucho. Ahora es imposible comprar nada. 'Prices have increased a lot. Now it is impossible to buy anything.'

(397) Ha viajado muchas veces a Europa. 'He/she has travelled many times to Europe.'

(398) He vivido treinta años aquí y conozco bien este país. 'I have lived here thirty years and I know this country well.'

(399) Hoy, Luisa ha salido del trabajo a las ocho.

'Today, Luisa has left her workplace at eight.'

(400) !!Luisa se ha divorciado el mes pasado!!

'Luisa has got divorced last month!!'

He defines the procedural meaning of the Spanish compound past as follows:

- The hearer must represent an eventuality of any type as bounded, locate it in the past and consider some kind of relation between $\mathrm{E}$ and $\mathrm{S}$ (via an R connected to S)

Aménos-Pons comments that the relation $\mathrm{E}<\mathrm{S}$ is common to all interpretations, but has a changing nature. Both resultative and existential interpretations convey the idea that an event has taken place, causing a result state that is thought to hold at $\mathrm{S}$ 
(though the result state has a different source for each of the two interpretations). In hodiernal and hot news interpretations, the eventuality is seen as closely connected to $\mathrm{S}$ without any result state represented (closeness being chronologically established for the former and speaker-based for the latter). Finally, in universal interpretations no result state is represented, since the eventuality is still going on.

Two other parameters that influences the interpretation of the compound past in Spanish is Aspect (perfective vs. imperfective viewpoint) and Aktionsart (telic vs. atelic eventualities). Perfective tenses provide bounded representations of eventualities, and thus they tend to associate with telics. Aménos-Pons argues that, being perfective, the compound past instructs the hearer to build a bounded representation of the eventuality, regardless of its type (telic or atelic). As far as the role of lexical aspect is concerned, telics are particularly compatible with resultative interpretations of the compound past. This is due to the fact that they have natural endpoints and involve a change of state. Aménos-Pons points out that the relation between resultative interpretations and telics is not systematic (there are cases of resultative interpretation arising with atelics, and interpretations without a result state with telics). He suggests that this is due to the flexible conceptual nature of lexical aspect, which accepts contextual adjustment if required, according to the criterion of consistency with the principle of relevance.

For Aménos-Pons, the procedural content of an indicative verbal tense influences its chances of occurring in narratives. Narratives require the temporal localization of eventualities in relation to each other chronologically. In the case of the Spanish compound past, the temporal localization of a bounded eventuality (in relation to $\mathrm{S}$ and its resulting state holding at S) minimizes the Spanish compound past's chances of occurring in narratives. On the other hand, the Spanish simple past, which does not involve a direct relation between $\mathrm{E}$ and $\mathrm{S}$, is preferred in narratives. The procedural meaning of the Spanish simple past is described in the following terms (Aménos-Pons 2011, 248):

- The hearer must represent an eventuality of any type as bounded and locate it in the past (via an $\mathrm{R}$ disconnected from $\mathrm{S}$ )

The Spanish simple past is also a perfective tense, therefore envisaging both telic and atelic eventualities as bounded. This illustrates that grammatical aspect has the same effect on eventuality type, for both verbal tenses.

Aménos-Pons' explanation of the procedural meaning of verbal tenses in Spanish gives rise to a very intriguing conclusion: procedural information encoded by a verbal tense provides aspectual information. A similar explanation is given by de Saussure (2003), who assumes that, when treating temporal reference expressed by a verbal tense, the human brain 'applies an aspectual strategy for building cognitive representations of eventualities' (de Saussure 2003, 179).

An initial drawback to de Saussure's model is the usage of the generic notion verbal tense, which does not foresee a distinction between Tense and Aspect with respect to their roles in building mental representations of eventualities. De Saussure's model assumes that verbal tenses encode procedural information providing aspectual information. One of the problems of this approach, where temporal 
information and aspectual viewpoint are mingled, is that it might lead to confusion regarding the semantic meaning of a verbal tense and its pragmatic uses. Secondly, it cannot be applied for a language other than that on which the model was developed, such as languages where the distinction between Tense and Aspect is more relevant, including other tense-prominent languages like English where progressive aspect is morphologically marked, aspect-prominent languages, and tenseless languages.

The second drawback is the overwhelming emphasis given to the category Tense in Western European studies of Romance languages. Treating verbal tenses in this way prompts ambiguous temporal and aspectual interpretations of verbal tenses, and discourages scholars contrasting verbal tenses cross-linguistically (see also Jaszczolt 2005, 2009, 2012) and building an accurate understanding of how temporal reference is expressed in natural language.

Finally, any analysis of verbal tenses should also provide answers to questions about the status of eventuality type (because of their very rich inter-relations), the status of Aspect (perfective and imperfective, Comrie 1976), and the way in which these types of meanings relate to each other. The current literature suggests that eventuality type has a conceptual nature (Moeschler 1994), that grammatical aspect encodes procedural information (Žegarac 1991; Leonetti and Escandell-Vidal 2003), and that these types of information are hierarchically organized (Moeschler 2000a).

\subsubsection{Verbal Tenses as Procedural Expressions: Temporal Relations}

Wilson and Sperber (1998) discussed the temporal (and causal) relations of conjoined propositions (as well as the case of and), and suggested that they are pragmatically determined aspects of what is said, and thus part of explicatures. They argue that the treatment of utterances' temporal and causal connotations requires consideration of three interrelated issues: the interval problem; the causeconsequence problem; and the temporal order problem. The interval problem is shown by examples (401) and (402), where the hearer assumes different time intervals: almost instantaneous in the former, and a much larger interval in the latter. The cause-consequence problem is shown by examples (401) and (403), where the hearer assumes that the glass broke because it was dropped, as in the former, and that Mary got angry because Peter left, as in the latter.

(401) John dropped the glass. It broke.

(402) They planted an acorn. It grew.

(403) Peter left. Mary got angry. 
The source of the cause is different in these two examples: it is conceptual in the former, and speaker-based in the latter. Finally, the sequencing problem is shown by example (403), where the hearer would assume that Peter left before Mary got angry.

(404) I took out my key. I opened the door.

As far as the interval issue is concerned, Wilson and Sperber (1998) point out that it also applies to single sentences, such as (405) and (406). If, by way of verbal tense, the eventuality is located at some point within an interval stretching back from the moment of speech S, the hearer's task is to choose from a series of logical possibilities: within the last few minutes, within the last few hours, within the last few days, weeks, months, etc. Wilson and Sperber argue that the hearer's choice affects the truth-conditions of the proposition and its cognitive effects. If the negation test is applied to verify the truth-conditional status, as in (407) and (408), the claim that the speaker has not had breakfast may be true within the last few minutes or hours, but false if the time interval refers to the last few weeks. The hearer's cognitive effects resulting from the processing of the sentence are greater for narrower intervals than for larger intervals.

(405) I have had breakfast.

(406) I have been to Tibet.

(407) I have not had breakfast.

(408) I have not been to Tibet.

Wilson and Sperber claim that the logical structure of the proposition is completed by the hearer's choice of the interval. This information is part of the explicature of the sentence. In the search for optimal relevance, the hearer narrows the interval according to contextual assumptions and encyclopaedic knowledge (or ready-made schema, such as taking a key and immediately using it to open the door, or having breakfast each morning) until he has an interpretation consistent with the communicative principle of relevance. In cases where no ready-made schema exists, such as in (409), the hearer might either make the hypothesis that the two events are unrelated and happened simultaneously or, in a very specific context (such as detective story for example), make the hypothesis that John used the handkerchief to open the door in order to avoid leaving fingerprints. In this case, there is an expectation of relevance for later justifying the use of the handkerchief.

(409) John took out his handkerchief and opened the door.

As far as the cause-consequence problem is concerned, causality is an important part of human cognition, ${ }^{13}$ allowing language users to predict the consequences of

\footnotetext{
${ }^{13}$ See, for example, Hume (1738), Davidson (1967, 1980), Talmy (1988) and more recent discussions such as Moeschler (2007), Reboul (2007), Blochowiak (2009, 2014b), among others.
} 
their own actions and those of others. Relevance Theory assumes, as Wilson and Sperber (1998) point out, that cause-consequence schemas are highly accessible to the mind for the interpretation of sentences like (403). According to the communicative principle of relevance, the information that Peter left must contribute to the overall cognitive effects. If this is the case, all other possible interpretations will be discharged.

Moeschler (2000a, 2002b) discusses the advantages of relevance-theorists' explanation of the status of temporal and causal inferences. Firstly, the temporal interpretation corresponds to a pragmatic enrichment of the propositional form of the sentence, and contributes to its truth conditions. In example (410), from Wilson and Sperber $(1998,171)$, the disjunction is not redundant because each disjunct brings a genuine contribution to the truth-conditions of the utterance. This is based on the assumption that the events presented in each disjunct happened in a different order.

(410) It's always the same at parties: either I get drunk and no-one will talk to me or no-one will talk to me and I get drunk.

Secondly, relevance theorists' explanation focuses on processing efforts rather than cognitive effects. Examples (405)-(408), with the compound past, produce two interpretations (either forward temporal inference or backward causal inference), and neither syntactic nor semantic structures indicate how the sentence should be interpreted. The interpretation is consistent with the communicative principle of relevance. This means that a temporal or a causal interpretation will be chosen, depending on which manifest facts are more accessible to the hearer, and based on the mutual cognitive environment.

Thirdly, forward temporal inference, i.e. the temporal order, and backward causal inference, i.e. the reverse-causal interpretation, are not the only possible relations between eventualities. There are two other possible relations, namely simultaneity as in (411), and indeterminacy as in (412).

(411) Bill smiled.

He smiled sadly. (Wilson and Sperber 1998)

(412) Cette nuit-là, notre héros but la moitié d'une bouteille de whisky et écrivit une lettre à Lady Ann.

That night, our hero drink.3SG.PS half a bottle of whisky and write.3SG.PS a letter to Lady Anne

'That night, our hero drank half a bottle of whisky and wrote a letter to Lady Anne.'

Moeschler (2000b) defines simultaneity and indeterminacy as follows:

- Simultaneity: $\mathrm{E}_{1}$ covers (partially) $\mathrm{E}_{2}$, which is a part of the eventuality denoted by $\mathrm{E}_{1}$ is included in the temporal interval defining $\mathrm{E}_{2}$ 
- Indeterminacy: the relation between $\mathrm{E}_{1}$ and $\mathrm{E}_{2}$ is undetermined if determining the relation is not necessary for understanding $\mathrm{E}_{1}$ and $\mathrm{E}_{2}$ or if determining the relation is not possible.

Fourthly, temporal order does not seem to be central to temporal coherence in discourse. Causality plays an important role, raising the question of the relation between temporality and causality. In example (413), the only possible relations are forward causal and temporal relations, while in (414), several relations are possible (forward temporal and causal, forward temporal and backward causal, or backward temporal and causal).
Socrate but
un coup et tomba
raide.
Socrates drink.3SG.PS a mouthful and fall.3SG.PS stone
'Socrates drank a mouthful and fell down dead.'
Marie cria
et Pierre partit.
Mary scream.3SG.PS and Peter leave.3SG.PS
'Mary screamed and Peter left.'

These examples suggest that causal relations are a subset of temporal relations. Wilson and Sperber (1998) give an example where a causal relation occurs without a temporal relation, as in (415).

\section{(415) Susan is underage and can't drink.}

Moeschler's proposal is that causal and temporal relations are two sets of relations that can have a Boolean junction. This means that, for two eventualities $\mathrm{E}_{1}$ and $\mathrm{E}_{2}$, there can be an intersection of causal and temporal relations for which $\left[\mathrm{E}_{1}\right.$ causes $\left.E_{2}\right]$ implicates $\left[E_{1}\right.$ precedes $\left.E_{2}\right]$. Two sentences can produce identical cognitive effects on the basis of different explicatures and implicated premises, as in (416) and (417). In (416), the temporal relation $\left[E_{1}\right.$ precedes $\left.E_{2}\right]$ is part of the explicature while the causal relation $\left[\mathrm{E}_{1}\right.$ causes $\left.\mathrm{E}_{2}\right]$ is an implicated premise. In (417), the causal relation $\left[\mathrm{E}_{1}\right.$ causes $\left.\mathrm{E}_{2}\right]$ is part of the explicature, while the temporal relation $\left[\mathrm{E}_{1}\right.$ precedes $\mathrm{E}_{2}$ ] is part of the implicated premise.

$$
\begin{aligned}
& \text { Max a laissé tomber le verre }\left(\mathrm{E}_{1}\right) \text {. Il s'est cassé }\left(\mathrm{E}_{2}\right) \text {. } \\
& \text { Max dropp.3SG.PC the glass. It break.3SG.PC } \\
& \text { 'Max dropped the glass. It broke.' }
\end{aligned}
$$

(417) Le verre s'est cassé $\left(\mathrm{E}_{2}\right)$. Max l'a laissé tomber $\left(\mathrm{E}_{1}\right)$.

The glass break.3SG.PC. Max it dropp.3SG.PC

'The glass broke. Max dropped it.'

I have stated above that there are several types of possible relations between eventualities, as summarized in Fig. 2.2, which considers temporal and causal relations. As far as temporal relations are concerned, they may or may not be forward temporal inferences (temporal sequencing). In the case where there is no temporal 


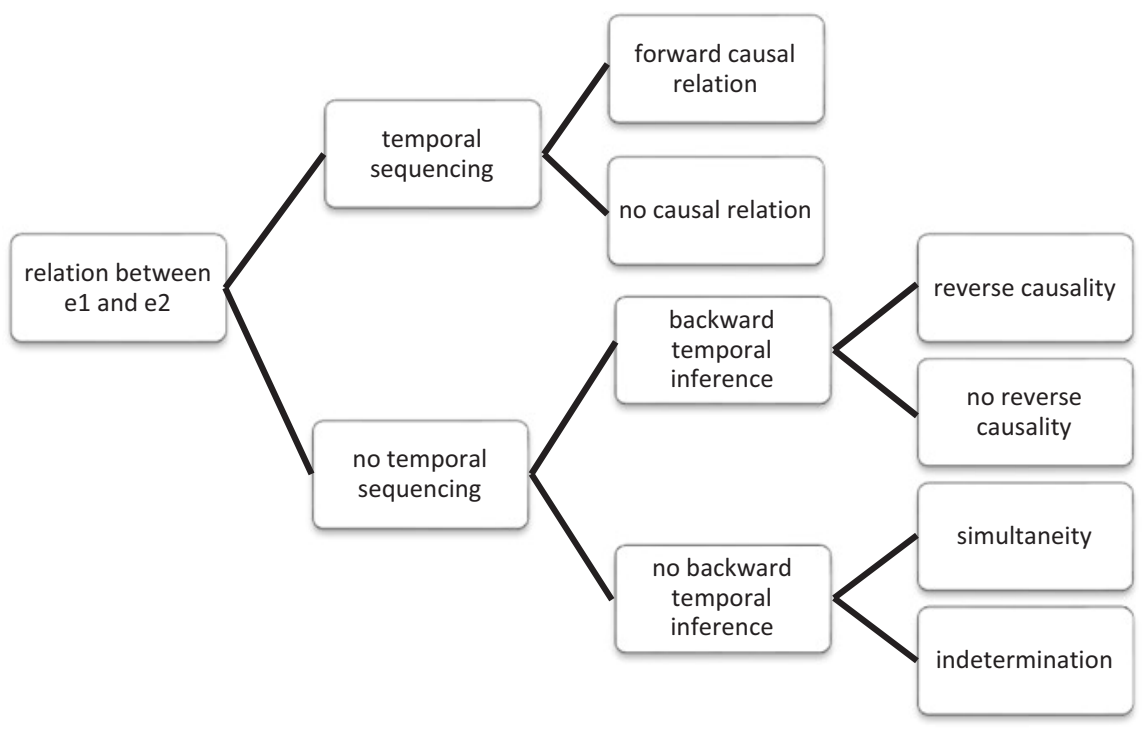

Fig. 2.2 Possible relations between eventualities

sequencing, there are two new possibilities: either there is or is not a backward temporal inference. And finally, if there is no backward temporal inference, then the cases of temporal simultaneity or indetermination can be identified. Temporal sequencing may or may not be accompanied by a forward causal relation, as in (413) and (415) respectively. Backward temporal inference may or may not be accompanied by reverse causality, as in (418) and (419) respectively.

(418) Max tomba. Jean l'avait poussé.

Max fall.3SG.PS. John him push.3SG.PQP

'Max fell. John had pushed him.'
Jean prépara
son café.
Il s'était levé
sans entrain.

John prepare.3SG.PS his coffee. He RFX wake up.3SG.PQP without energy 'Jean prepared his coffee. He woke up without energy.'

Moeschler's principle of temporal interpretation of the discourse is that, during the comprehension process, the hearer makes inferences about the temporal sequencing of eventualities, which are forward or backward temporal inferences. In SDRT, these correspond roughly to the discourse relations Narration and Explanation respectively. These are not default inferences (in contrast to SDRT, where Narration is the default inference), but are driven by linguistic expressions (encoding procedural and conceptual information) and non-linguistic information (contextual hypotheses and encyclopaedic knowledge).

Of procedural expressions, the most relevant for temporal interpretation at the discursive level are connectives and verbal tenses. For example, the conceptual rela- 
tion holding between the verbs pousser-tomber ('push-fall') and the compound past expresses a forward temporal and causal relation in (420), and a backward temporal and causal relation in (421). Examples (422) and (423) illustrate how the insertion of the connective changes the direction of the temporal and causal relation: backward in the former (despite the forward direction conveyed by the conceptual relation), encoded by the connective parce que ('because'); and forward in the latter, encoded by the connective et ('and').

(420) Marie a poussé Jean. Il est. tombé.

'Mary pushed John. He fell.'

(421) Jean est. tombé. Marie l'a poussé. 'John fell. Mary pushed him.'

(422) Marie a poussé Jean parce qu'il est tombé.

'Mary pushed John because he fell.'

(423) Jean est. tombé et Marie l'a poussé.

'John fell and Mary pushed him.'

Examples (426)-(429) illustrate the relation between verbal tense and connective. The Passé Simple in (424) and (425) conveys a forward temporal direction. The examples in (426) and (427) illustrate the compatibility of the Passé Simple with the connective $e t$, which explicitly expresses the forward temporal relation. Example (428) demonstrates the incompatibility of the Passé Simple, conveying a forward relation, and the connective parce que, which imposes a backward relation. This incompatibility disappears in (429), where the backward relation is maintained by the conceptual relation between the verbs. As seen in examples (420)-(423), the Passé Composé is not directional (i.e. it does not impose a temporal direction), and is compatible with the direction imposed by the conceptual relation pousser-tomber ('push-fall') and the connectives parce que 'because' and et 'and'.

(424) Marie poussa Jean. Il tomba. 'Mary pushed John. He fell.'

(425) Jean tomba. Marie le poussa. 'John fell. Mary pushed him.'

(426) Marie poussa Jean et il tomba. 'Mary pushed John and he fell.'

(427) Jean tomba et Marie le poussa. 'John fell and Mary pushed him.'

(428) ?Marie poussa Jean parce qu'il tomba. ?'Mary pushed John because he fell.'

(429) Jean tomba parce que Marie le poussa. 'John fell because Mary pushed him.'

The plus-que-parfait is the opposite of the Passsé Simple in this regard. It conveys a backward temporal relation, as in (430), and this relation is expressed explicitly by the connective parce que, in (431). Example (432) expresses the 
incompatibility of the plus-que-parfait, conveying a backward relation, and the connective $e t$, which imposes a forward relation.

(430) Marie poussa Jean. Il était tombé.

'Mary pushed John. He had fallen.'

(431) Marie poussa Jean parce qu'il était tombé.

'Mary pushed John because he had fallen.'

(432) ?Marie poussa Jean et il était tombé.

?'Mary pushed John and he had fallen.'

The model developed by Moeschler (2000a, 2002b) for the temporal interpretation of discourse is called the Model of Directional Inferences (MDI). The basic assumption is that, if linguistic and non-linguistic sources provide contradictory directional information, the conflict must be resolved in order to achieve the intended cognitive effects. The MDI postulates the following hierarchies for the various types of information that contribute to directional inferences (Moeschler 2000a, 7):

- Connectives $>>$ tenses $>>$ verbs

- Contextual assumptions $>>$ connectives $>>$ tenses $>>$ verbs

- Contextual information $>>$ linguistic information

- Contextual assumptions $>>$ procedural information $>>$ conceptual information

The first hierarchy considers the hypothesis that, in case of mismatches, the direction encoded by connectives prevails over the direction given by the verbal tense, which in turn prevails over the direction given by the verbs (the conceptual relation). The second and third hierarchies are based on the relevance-theoretic assumption that linguistic information is underdetermined, and is adjusted according to contextual assumptions. In case of mismatches, the direction given by contextual assumptions prevails over the direction given by linguistic expressions. Finally, the fourth hierarchy asserts that procedural information (provided by connectives and verbal tenses) prevails over conceptual information (provided by conceptual relations and situation types). Consequently, there is another assumption resulting from these hierarchies:

- verbs and verbal tenses bear weak directional features

- connectives and contextual assumptions bear strong directional features

Moeschler insists on the fact that the working hypotheses of the MDI should not be considered fixed rules, because they can be overturned $(2002 b, 9)$. His idea is that the hearer's access to the intended interpretation is governed by the principles of economy (as defined by Relevance Theory) and optimality (Prince and Smolensky 1993). In his words (2002b, 2):

The combination of linguistic and non-linguistic information is directed by the general principle of optimality. This principle states that an optimal interpretation minimizes the conflict information: the less conflict you meet, the more optimal the interpretation you get. 
For de Saussure (2003), one of the MDI model's limitations comes from the prediction that the strong directional features given by connectives and contextual assumptions will always provide the temporal interpretation of the discourse. As a result, it is unclear what concrete role is played in discourse interpretation by the weak directional features given by verbal tenses and verbs. The second limitation regards the identification of accessible contextual assumptions. De Saussure points out three possible cases: (a) if contextual assumptions are built according to the presence of connectives (such as parce que or $e t$ ), then the inference is triggered by linguistic expressions, meaning that the directional features given by contextual assumptions and connectives do not represent several features but are options linked to only one feature; (b) if contextual assumptions are built according to conceptual rules, then the directional features given by contextual assumptions and verbs represent, again, one and the same feature; and (c) if contextual assumptions are built according to other contextual information, then this must be explained in the model.

The third limitation concerns ambiguous examples. This is the case of temporal indeterminacy, where no temporal direction can be determined, that is to determine whether partially or totally covering whole-subpart relations, and cases where eventualities take place simultaneously (i.e. temporal simultaneity). Indeterminacy, in (433)-(435), and simultaneity, in (436), are classic problematic examples (Kamp and Rohrer 1983; Moeschler and Reboul 1998; de Saussure 2003). In such cases, the MDI's explanation is that a contextual hypothesis, coming from general world knowledge or conceptual rules, cancels the temporal direction provided by other sources, such as verbs, tenses or connectives. The MDI does not provide mechanisms to allow for non-directional temporal inferences, as in these examples, with the Passé Simple.

(433) L'été de cette année là vit de nombreux changements dans la vie de nos héros. François épousa Adèle, Jean-Louis partit pour le Brésil et Paul s'acheta une maison à la campagne.

'The summer of that year saw several changes in our heroes' lives. François married Adele, Jean-Louis left for Brazil and Paul bought a house in the countryside.'

(434) Cette nuit-là, notre héros but une bouteille de whisky et écrivit une lettre à Lady Ann.

'That night, out hero drank a bottle of whisky and wrote a letter to Lady Ann.'

(435) Max construisit un château de cartes. Il était paisiblement à la maison. 'Max built a house of cards. He was at home, in peace.'

(436) Bianca chanta et Pierre l'accompagna au piano.

'Bianca sung and Igor accompanied her on the piano.'

I would like to argue that both Moeschler's model (MDI) and de Saussure's procedural model (PM) are potentially accurate models for French verbal tenses with respect to how the hearer processes temporal information at the discursive level. 
The two models have both similarities and dissimilarities. As far as similarities are concerned, I can suggest the following:

- They are both fine-grained models of semantic and pragmatic sources of temporal information.

- Both models make use of the conceptual and procedural information from linguistic expressions-namely, verbal tenses, connectives and temporal adverbials.

- Neither proposal models grammatical and lexical aspect concretely (one exception might be the PM's suggestion that a verbal tense such as the French Passé Composé triggers a perfective representation of the process).

- In both models, the interpretation process is driven by the pursuit of relevance.

- Both models are theoretical models, and lack consistent and objective empirical bases, such as corpus analyses and the experimental validation of hypotheses.

- They are both monolingual models, and lack therefore cross-linguistic perspective.

I would identify the following dissimilarities between the models:

- The PM assumes that a verbal tense provides a temporal direction by default, whereas the MDI does not.

- The PM makes use of temporal relations, whereas MDI makes use of both temporal and causal relations holding between eventualities.

- The two models suggest a similar method for resolving potentially conflicting information: a hierarchy of features in MDI, and a conditional procedure (i.e. of the if...then type) making use of the same hierarchy of features in the PM.

In more recent research, Moeschler and colleagues (Moeschler et al. 2012; Grisot and Moeschler 2014; Moeschler 2016) propose and defend the mixed conceptualprocedural model of verbal tenses (MCPM). The MCPM, more flexible than the MDI model, has been successfully tested and validated on empirical data such as the English Simple Past, and the French Passé Composé, Passé Simple, Imparfait and Présent Historique (Grisot and Moeschler 2014; Moeschler 2014).

The MCPM is based on a classical Reichenbachian analysis of verbal tenses, supplemented by further pragmatic features. The use of S, R and E, as well as temporal relations of precedence and simultaneity (both co-extensional and inclusive), provides a general tense system template distinguishing between the sub-systems: one for past tenses, and the other for present and future tenses (Moeschler 2016, 130). The MCPM proposes a maximum of six pragmatic uses of verbal tenses, extrapolated from the following hierarchy of features: $[ \pm$ narrative $]>[ \pm$ subjective $]>[ \pm$ explicit $]$. The $[ \pm$ narrative $]$ feature indicates whether or not temporal ordering is obtained by use of the current verbal tense; [ \pm subjective] refers to the presence or absence of a point of view (perspective or self in Banfield 1982); and finally, the [ \pm explicit] feature signals whether the perspective is explicitly mentioned or implicitly accessed, as shown in Fig. 2.3.

For Moeschler $(2016,130)$, 


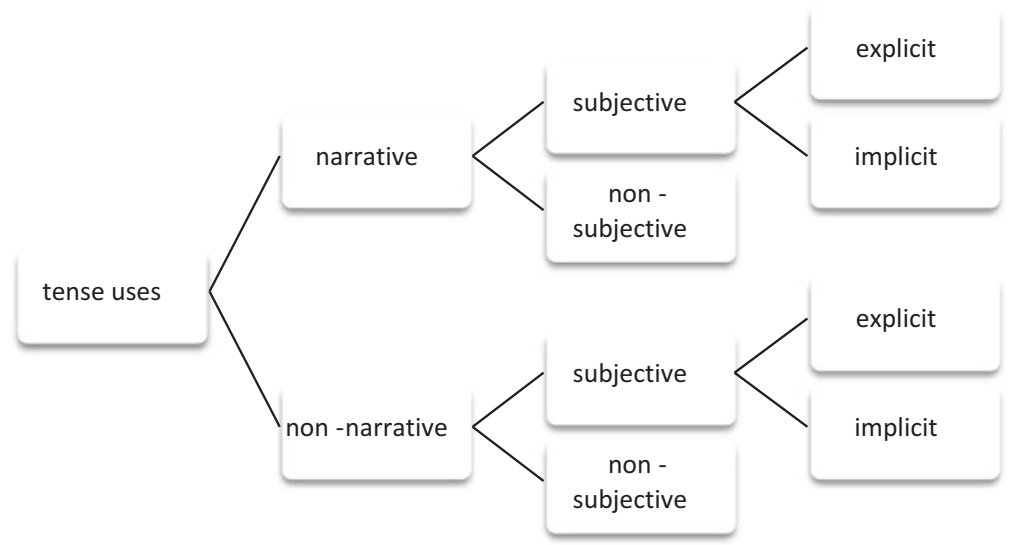

Fig. 2.3 Types of uses for tenses

Table 2.3 Conceptual and procedural analysis of the French Passé Simple (PS) and Imparfait (IMP)

\begin{tabular}{|c|c|c|c|c|c|}
\hline \multirow[b]{2}{*}{ Tenses } & \multirow[b]{2}{*}{ Meanings/Usages } & \multirow[b]{2}{*}{ Conceptual } & \multicolumn{3}{|c|}{ Procedural } \\
\hline & & & Narrative & Subjective & Explicit \\
\hline \multirow[t]{2}{*}{ PS } & PS1 & \multirow[t]{2}{*}{$\mathrm{E}=\mathrm{R}<\mathrm{S}$} & + & - & - \\
\hline & PS2 & & + & + & + \\
\hline \multirow[t]{4}{*}{ IMP } & IMP1 & \multirow[t]{4}{*}{$\mathrm{E} \supseteq \mathrm{R}<\mathrm{S}$} & + & + & - \\
\hline & IMP2 & & - & + & + \\
\hline & IMP3 & & - & + & - \\
\hline & IMP4 & & - & - & - \\
\hline
\end{tabular}

Pragmatic outputs of the interpretation of tenses are of the same kinds (they are defined by the values of these three features), whereas their differences lie in their semantics, that is, the relation between $\mathrm{S}, \mathrm{R}$ and $\mathrm{E}$ they encode.

In other words, verbal tenses have a robust semantic component given by the different configurations of Reichenbachian temporal coordinates, which are encoded at the conceptual level, and pragmatic uses provided by the three features of the model, as shown in Table 2.3, from Moeschler $(2016,135)$. The table also indicates that, in actual usage, not all verbal tenses have all six of the usages predicted by the MCPM model. For example, the French Passé Simple has two main usages: [+narrative] [-subjective], as in (437), and [+narrative] [+subjective] [+ explicit], as in (438).

(437) Max entra dans le bar. Il alla s'asseoir au fond de la salle.

'Max entered the bar. He sat down at the back of the room.'

(438) Aujourd'hui, personne ne lui adressa la parole. (Stendhal, Le rouge et le noir)

'Today, no one spoke to him.' 
The model of temporal reference defended in Chap. 5, the Highly Discriminatory model, offers large empirical and cross-linguistic testing of the theoretical assumptions behind the MDI and PM models, which were based only on French verbal tenses, as well as the MCPM model, which makes use of the generic notion of verbal tense, thus without distinguishing between the categories of Tense, Aktionsart and Aspect.

\subsection{Summary}

This chapter was dedicated to discussing formal semantic-discursive and pragmatic assessments of temporal cohesive ties. As in Chap. 1, it is evident that most scholars consider the notion of verbal tense to be relevant when determining temporal cohesion and temporal coherence in a discourse. Nevertheless, some of them have specifically focused on the role played by aspectual classes, for example, in order to explain the phenomena of temporal sequencing (also referred to by researchers working on coherence as chronological sequential temporal relations) and temporal simultaneity (also referred to as synchronous or simultaneity temporal relations) (see Chap. 6).

I have discussed a series of formal semantic-discursive accounts, such as Bennet and Partee's logical approach within a compositional semantics account, Partee's (1973, 1984) and Hinrich's (1986) treatment of verbal tenses as temporal anaphors, as well as the implementation of this idea in Kamp's discourse representation theory. As for Dowty's and ter Meulen's proposals focusing on the role of aspectual classes, the main drawback seems to be the rigidity of the rules employed by their models. Broadly, despite their accuracy in explaining temporal information provided by the language system, the main limitation is their inability to account for the aspects of meaning which are not encoded and which depend on the hearer's interpretation of the discourse.

Consequently, I have addressed a series of pragmatic assessments of time, such as the Gricean, neo-Gricean and post-Gricean accounts. I have focused on Relevance Theory, which-due to its cognitive foundations of the language comprehension process-is a suitable framework for developing robust accounts of Tense, Aktionsart, Aspect and their roles as cohesive ties. A central assumption of Relevance Theory is that the linguistic expressions that a speaker utters underdetermine the content that she communicates, not only at the level of implicatures but also the propositional content she communicates explicitly (that is, the explicature of the utterance). The hearer must therefore recover inferentially the speaker's intended meaning, at the levels of explicature and implicature. Another proposition of Relevance Theory is that linguistic expressions encode conceptual information and 
procedural information (i.e. instructions for manipulating conceptual representations) which contribute to and constrain the interpretative process, respectively.

As such, I have discussed previous proposals according to which Aktionsart encodes conceptual information whereas Tense and Aspect represent instructions for the manipulation of these conceptual representations. In this chapter, I have shown that temporal relations holding between eventualities could be seen as semantic discourse relations (in DRT), as default interpretations associated with individual verbal tenses (as in Kamp and Rohrer 1983, Moeschler 2000a, 2002b, and de Saussure 2003), as conversational implicatures (as suggested by Grice), or as pragmatically determined aspects of what is said (as suggested by Wilson and Sperber 1998). In Chap. 5, and based on the experiments discussed in Chap. 4, I will argue that temporal relations holding between eventualities represent procedural information encoded by the category of Tense. The data tested in these experiments are drawn from bilingual and multilingual corpora which I explored and analysed. The following chapter is devoted to this topic.

Open Access This chapter is licensed under the terms of the Creative Commons Attribution 4.0 International License (http://creativecommons.org/licenses/by/4.0/), which permits use, sharing, adaptation, distribution and reproduction in any medium or format, as long as you give appropriate credit to the original author(s) and the source, provide a link to the Creative Commons license and indicate if changes were made.

The images or other third party material in this chapter are included in the chapter's Creative Commons license, unless indicated otherwise in a credit line to the material. If material is not included in the chapter's Creative Commons license and your intended use is not permitted by statutory regulation or exceeds the permitted use, you will need to obtain permission directly from the copyright holder.

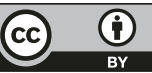

